INL/EXT-15-36637

Draft Revision: 0

\title{
NEET Enhanced Micro-Pocket Fission Detector for High Temperature Reactors - FY15 Status Report
}

T.Unruh, D. McGregor, P. Ugorowski, M. Reichenberger, T. Ito

September 2015

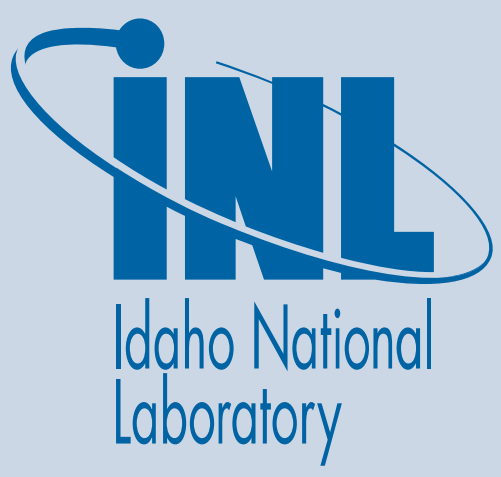

The INL is a U.S. Department of Energy National Laboratory operated by Battelle Energy Alliance 


\section{DISCLAIMER}

This information was prepared as an account of work sponsored by an agency of the U.S. Government. Neither the U.S. Government nor any agency thereof, nor any of their employees, makes any warranty,

expressed or implied, or assumes any legal liability or responsibility for the accuracy, completeness, or usefulness, of any information, apparatus, product, or process disclosed, or represents that its use would not infringe privately owned rights. References herein to any specific commercial product, process, or service by trade name, trade mark, manufacturer, or otherwise, does not necessarily constitute or imply its endorsement, recommendation, or favoring by the U.S. Government or any agency thereof. The views and opinions of authors expressed herein do not necessarily state or reflect those of the U.S. Government or any agency thereof. 


\section{EXECUTIVE SUMMARY}

A new project, that is a collaboration between the Idaho National Laboratory (INL), the Kansas State University (KSU), and the French Atomic Energy Agency, Commissariat à l'Énergie Atomique et aux Energies Alternatives, (CEA), has been initiated by the Nuclear Energy Enabling Technologies (NEET) Advanced Sensors and Instrumentation (ASI) program for developing and testing High Temperature Micro-Pocket Fission Detectors (HT MPFD), which are compact fission chambers capable of simultaneously measuring thermal neutron flux, fast neutron flux and temperature within a single package for temperatures up to $800^{\circ} \mathrm{C}$.

The MPFD technology utilizes a small, multi-purpose, robust, in-core parallel plate fission chamber and thermocouple. As discussed within this report, the small size, variable sensitivity, and increased accuracy of the MPFD technology represent a revolutionary improvement over current methods used to support irradiations in US Material Test Reactors (MTRs).

Previous research conducted through NEET ASI ${ }^{1-3}$ has shown that the MPFD technology could be made robust and was successfully tested in a reactor core. This new project will further the MPFD technology for higher temperature regimes and other reactor applications by developing a HT MPFD suitable for temperatures up to $800^{\circ} \mathrm{C}$.

This report summarizes the research progress for year one of this three year project. Highlights from research accomplishments include:

- A joint collaboration was initiated between INL, KSU, and CEA. Note that CEA is participating at their own expense because of interest in this unique new sensor.

- An updated HT MPFD design was developed.

- New high temperature compatible materials for HT MPFD construction were procured.

- Construction methods to support the new design were evaluated at INL.

- Laboratory evaluations of HT MPFD were initiated.

- Electrical contact and fissile material plating has been performed at KSU.

- Updated detector electronic evaluations have been initiated at KSU.

- A project meeting was held at KSU to discuss the roles and responsibilities between INL and KSU for development of the HT MPFDs.

- Providing input to various irradiation programs for installation of the MPFD technology in their irradiation tests.

As documented in this report, FY15 funding has allowed the project to meet year one planned accomplishments to develop a HT MPFD. In addition, the accomplishments of this project have attracted independent funding from other Department of Energy Office of Nuclear Energy (DOE-NE) programs for MTR irradiations of the MPFD technology. These are significant opportunities for this NEET Enhanced Micro-Pocket Fission Detector for High Temperature Reactors project because the irradiation expense of these experiments could not be included in the original project scope. 
NEET Enhanced Micro-Pocket Fission Detector for High Temperature Reactors - FY15 Status Report 


\section{CONTENTS}

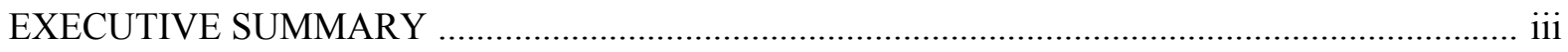

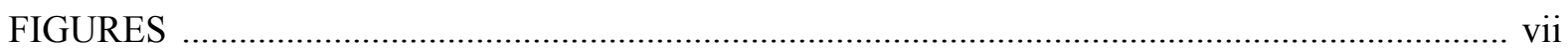

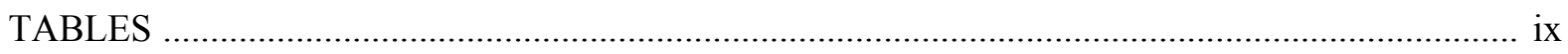

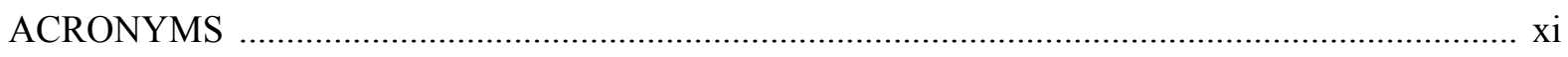

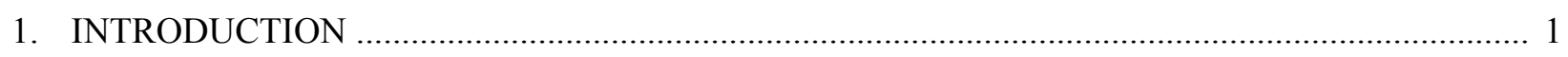

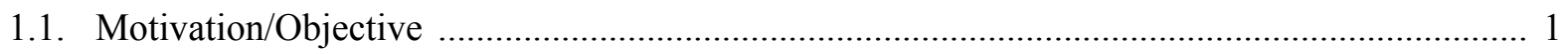

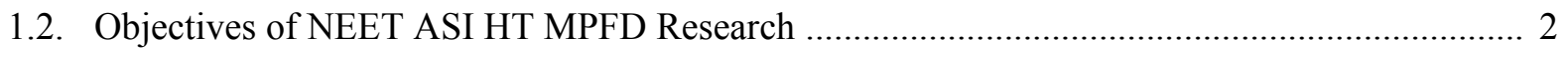

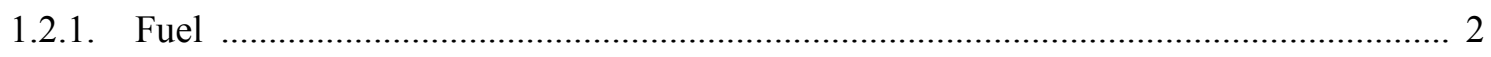

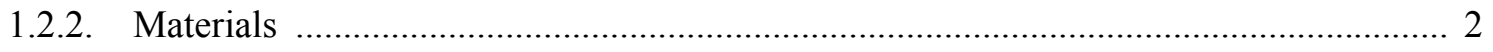

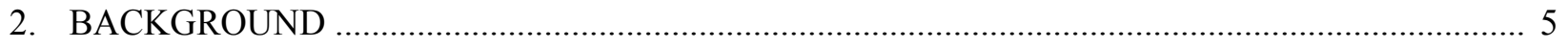

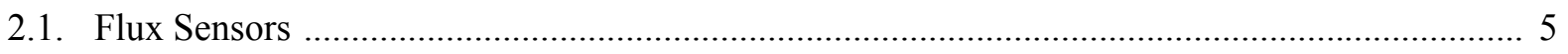

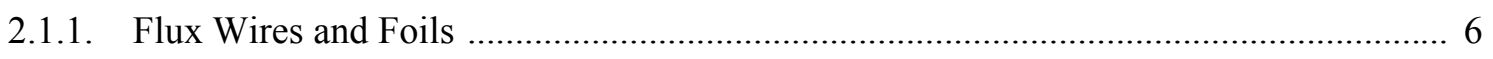

2.1.2. Self Powered Neutron Detectors ..................................................................... 7

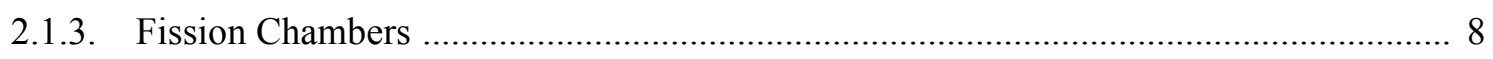

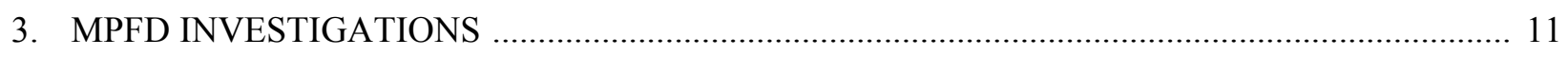

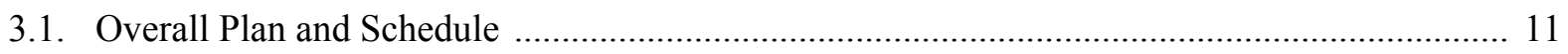

3.2. Prior Activities and Collaborator Capabilities ................................................................. 12

3.2.1. KSU MPFD Design and Evaluation Activities (Prior to Start of HT MPFD Project) . 12

3.2.2. NEET ASI MPFD Design and Evaluation Activities (Prior to Start of HT MPFD Project) 13

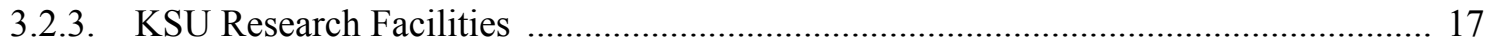

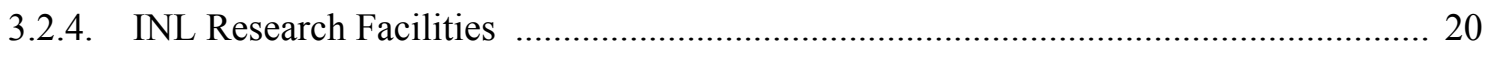

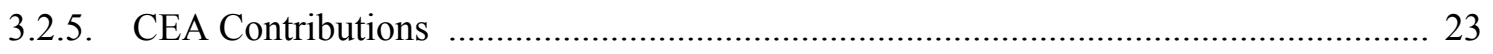

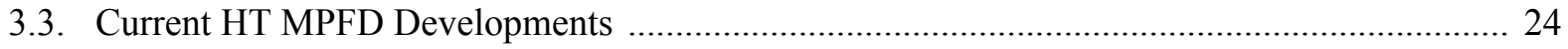

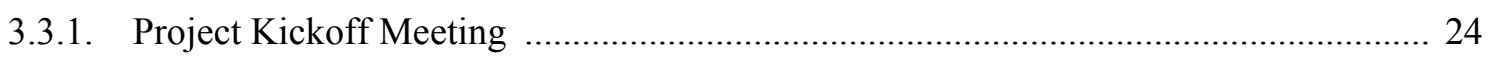

3.3.2. High Temperature Sensor Design for MTR Irradiations ........................................... 24

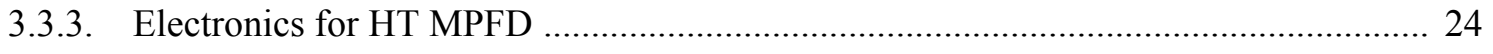

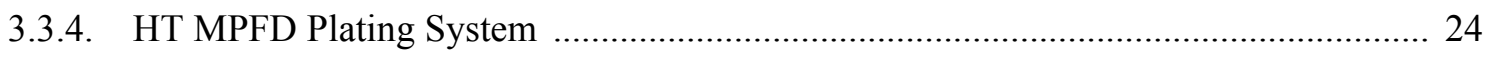

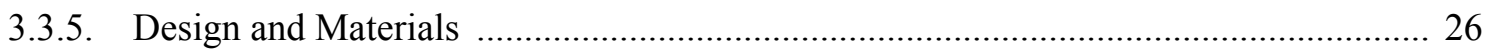

3.3.6. MPFD MTR Irradiation Opportunities ............................................................. 30

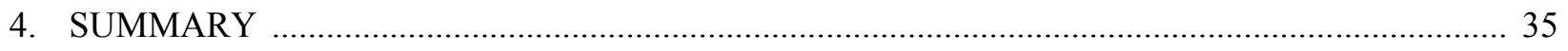

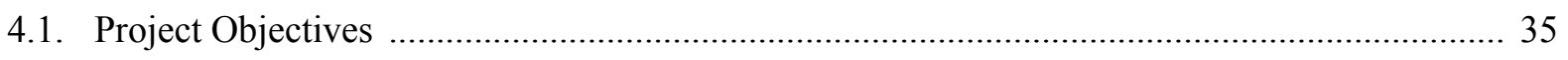

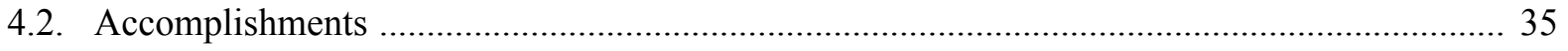

4.3. Importance of Superior Flux Detector .......................................................................... 36

4.4. Future Work ........................................................................................................... 36 
NEET Enhanced Micro Pocket Fission Detector for High Temperature Reactors - FY15 Status Report

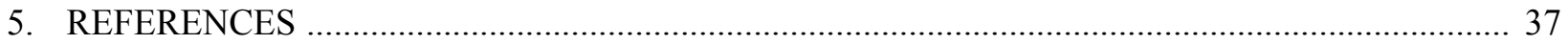




\section{FIGURES}

1. Representative flux wires, flux foils and test hardware used at INL ....................................... 6

2. Representative Self-Powered Neutron Detector (SPND) and component sketch ......................... 7

3. Representative fission chamber and component sketch ........................................................ 8

4. Representative CEA miniature fission chambers and component sketch ................................... 9

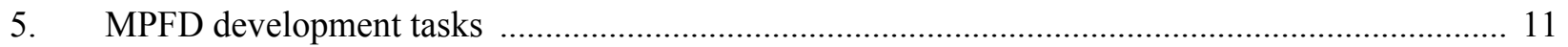

6. KSU MPFD component sketch (left) and initial KSU prototype MPFD (right) ......................... 12

7. Round geometry MPFD design suitable for MTR irradiations ................................................. 14

8. Component diagram of MPFD design showing wire locations .............................................. 14

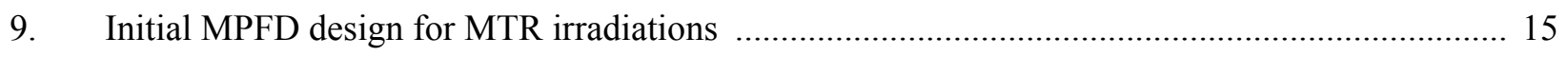

10. Leak testing an enhanced MPFD in specialized HTTL leak detection system ........................... 15

11. Round geometry MPFD installation into furnace and data acquisition system .......................... 16

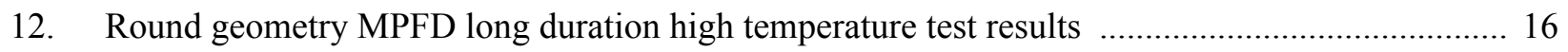

13. MPFD installation in the central thimble at KSU TRIGA reactor ............................................ 17

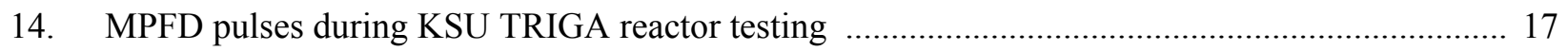

15. Electron-beam evaporator depositing material at the KSU SMART Laboratory …..................... 18

16. MPFD sample undergoing micro-electroplating of fissile material at the KSU SMART

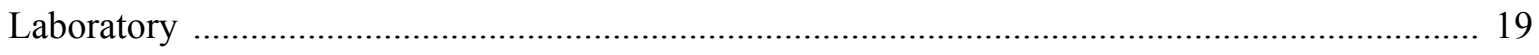

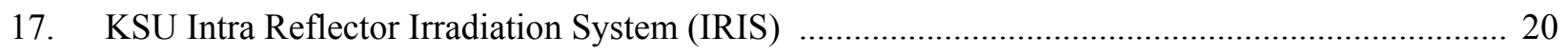

18. HTTL layout in the new Energy Innovation Laboratory ........................................................ 21

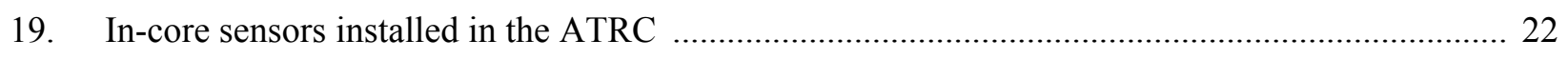

20. Axial flux profile and power measurements obtained from rhodium SPNDs and a fission

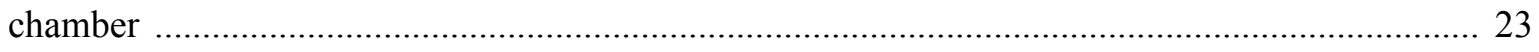

21. HTMPFD assembly shown in tube with thermocouple in extension cable ................................ 25

22. MPFD amplifier used for testing at KSU TRIGA reactor ................................................... 26

23. Analog and digital signals from MPFDs in KSU TRIGA reactor ............................................. 26

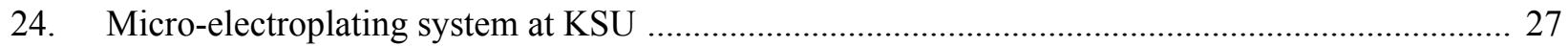

25. Electroplated sample of uranium under analysis with optical profilometer ............................... 28

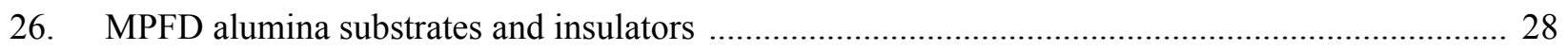

27. Extension cable with six wires threaded through insulation ................................................. 28

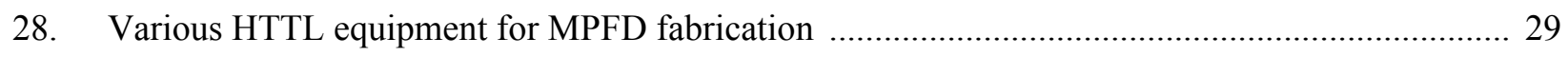

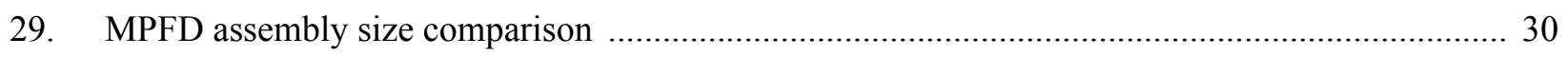

30. In-core sensor and equipment locations in the AGR 5/6/7 test ............................................ 31

31. Sensor locations near the fuel specimen in the Multi-SERTTA irradiation test vehicle for ATF-3; MPFD shown in purple

32. Overall layout of the Multi-SERTTA irradiation test vehicle for ATF-3; MPFD shown in 
NEET Enhanced Micro Pocket Fission Detector for High Temperature Reactors - FY15 Status Report

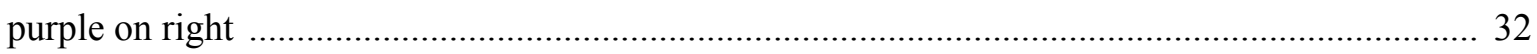

33. Transient MPFD for ATF-3 multi-SERTTA TREAT irradiation .............................................. 33 


\section{TABLES}

1 Summary of desired parameters for detection during fuel irradiation tests .................................... 3

2 Summary of desired parameters for detection during materials irradiation tests............................. 4

3 Summary of advantages and disadvantages of typical flux sensors ........................................... 5

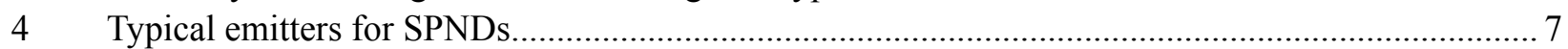


NEET Enhanced Micro Pocket Fission Detector for High Temperature Reactors - FY15 Status Report

September 2015 


\section{ACRONYMS}

AFC Advanced Fuel Cycle

AGR Advanced Gas-cooled Reactor

ART Advanced Reactor Technologies

ASI Advanced Sensors and Instrumentation

ATF Accident Tolerant Fuels

ATR Advanced Test Reactor

ATRC Advanced Test Reactor Critical facility

BTB Back-to-Back

BWR Boiling Water Reactor

CEA Commissariat à l'Énergie Atomique et aux Energies Alternatives

DOE Department of Energy

DOE-NE Department of Energy Office of Nuclear Energy

EDL Electronics Design Laboratory

EIL Energy Innovation Laboratory

EGT Experiment Guide Tube

FCRD Fuel Cycle Research and Development

FNDS Fast Neutron Detection System

FY Fiscal Year

HFIR High-Flux Isotope Reactor

HPIL Health Physics Instrument Laboratory

HTGR High Temperature Gas Reactor

HTIR-TC High Temperature Irradiation Resistant Thermocouple

HT MPFD High Temperature Micro-Pocket Fission Detector

HTTL High Temperature Test Laboratory

INL Idaho National Laboratory

IRP Integrated Research Project

KSU Kansas State University

LWR Light Water Reactor

LWRS Light Water Reactor Sustainability

MPFD Micro-Pocket Fission Detector

MTR Material Test Reactor

NEET Nuclear Energy Enabling Technology

NGNP Next Generation Nuclear Plant

NIST National Institute of Standards and Technology

NSUF National Scientific User Facility

ORNL Oak Ridge National Laboratory

PWR Pressurized Water Reactor

SFR Sodium Fast Reactor

SMART Semiconductor Materials And Radiological Technologies 
NEET Enhanced Micro-Pocket Fission Detector for High Temperature Reactors - FY15 Status Report

SMR Small Modular Reactors

SPND Self Powered Neutron Detector

TRIGA Training Research Isotope-production General Atomics

TREAT Transient REActor Test 


\section{NEET Enhanced Micro Pocket Fission Detector for High Temperature Reactors - FY15 Status Report}

\section{INTRODUCTION}

Irradiation testing, which is often performed in harsh conditions (e.g., high flux, high temperature, etc.) in Materials Test Reactors (MTRs), is essential for evaluating the performance of new materials and fuels prior to use in commercial reactors. Accurate monitoring of these harsh conditions with compact sensors, that are less likely to disturb the conditions of interest, is necessary to quantify any degradation that occurs during irradiation.

Miniature fission chambers and thermocouples have been used in-core at research and test reactors throughout the world; however, none have been deployed in a single compact package to survive the harsh conditions that exist within many tests conducted in MTRs. Previous research conducted through Nuclear Energy Enabling Technologies (NEET) Advanced Sensors and Instrumentation (ASI) ${ }^{1-3}$ has shown that the Micro-Pocket Fission Detector (MPFD) technology could be made robust and was successfully tested in a reactor core. However, it was recognized that a High Temperature MPFD (HT MPFD) would be of interest to irradiation test campaigns that test materials at elevated temperatures. The following report summarizes FY15 activities completed to develop a HT MPFD capable of measuring thermal neutron flux, fast neutron flux, and temperature within a single compact sensor for temperatures up to $800{ }^{\circ} \mathrm{C}$.

\subsection{Motivation/Objective}

During the last 40 to 50 years, various sensors have been developed to meet the needs of irradiation testing for materials and fuels in MTRs. Development of these sensors is an on-going process because they are continuously improved and refined to overcome operational shortcomings associated with more complicated irradiation testing requirements. Recent interest in testing to support new reactor designs can require higher temperatures, higher fluxes, or more corrosive test conditions. The next generation of sensors is under development that can survive these conditions.

In-core fission chamber design has remained relatively unchanged for decades. Improvements in performance, overall size, and operational modes have been implemented; however, all have been based on the same design that utilizes coaxial cylinders with a high pressure fill gas. These design considerations limit the robustness, lifetime, size, and operational performance of such sensors in high performance MTR environments.

The MPFD technology utilizes the same operational concept of existing fission chamber designs, but deploys different geometry, construction, materials and operational characteristics that are discussed further in Section 2.1.3.2. The small design also allows two or more of these neutron detectors and a thermocouple to be co-located within a single sensor sheath such that thermal flux, fast flux, and temperature can be simultaneously measured at very near the same location in the experiment with a single penetration in the experimental pressure boundary.

The MPFD technology offers the potential for improved, high accuracy, and higher fidelity data of interest to Department of Energy office of Nuclear Energy (DOE-NE) programs. Deployment of multiple compact HT MPFDs in irradiation tests will provide much needed information for current efforts to develop and deploy high-fidelity, multi-scale, multi-physics computer codes. 


\subsection{Objectives of NEET ASI HT MPFD Research}

Several DOE-NE programs, such as the Fuel Cycle Research and Development (FCRD), Advanced Reactor Technologies (ART), Light Water Reactor Sustainability (LWRS), Small Modular Reactors (SMR), and Next Generation Nuclear Plant (NGNP) programs, are investigating new fuels and materials for advanced and existing reactors. The NEET ASI in-pile instrumentation development activities are focused upon addressing cross-cutting needs for DOE-NE irradiation testing by providing higher fidelity, real-time data with increased accuracy and resolution from smaller, compact sensors that are less intrusive. ${ }^{4}$ In particular, flux sensors are required for characterizing fuel performance as a function of burnup and cladding and structural material degradation as a function of neutron exposure. The NEET ASI program initiated the HT MPFD project because it addresses this cross-cutting need by developing, fabricating, and evaluating the performance of compact multi-purpose fission chambers with integral temperature sensors that could survive up to $800{ }^{\circ} \mathrm{C}$.

A key objective of several DOE-NE programs is to understand the performance of candidate fuels and materials during irradiation. Hence, NEET research must produce sensors able to withstand the operating conditions of interest to these DOE-NE programs. It is also important that the sensors be able to measure test parameters with the desired accuracy and resolution required by these DOE-NE programs and that the sensors be compact to minimize their impact on irradiation test data. Recognizing that DOE-NE program needs change, the NEET program holds annual reviews to ensure that projects continue to meet DOE-NE program needs. Specific details related to requirements for thermal flux, fast flux, and temperature sensors requested by DOE-NE programs for fuels and material irradiations are summarized in this section.

\subsubsection{Fuel}

In-situ instrumentation is desired to provide real-time data on fuel performance phenomena. Currently, drop-in or static capsule experiments only allow data to be obtained at the endpoint of an experiment. Although visual examinations and material property measurements may be made on samples at the end of the test, such measurements are subject to error because of handling and because measurements are not made under prototypic pressures, fluxes, and/or temperatures. Sensors included in such tests can only provide insights about the integral neutron fluence or peak temperatures. In-situ sensors in irradiation tests with instrumentation leads can provide data showing the evolution of particular phenomena over time.

Clearly, real-time data obtained during an irradiation are advantageous. However, it is important to understand what additional sensors are needed to obtain data with the required accuracy and resolution. As part of this NEET effort, appropriate documents were reviewed and cognizant technical experts were contacted to gain insights related to the temperature, flux levels, and fluences proposed for fuel irradiation tests. Results from this review are summarized in Table 1.

\subsubsection{Materials}

Using a Light Water Reactor (LWR) as an example, there are many different types of materials that makeup the construction; over 25 different metal alloys can be found within the primary and secondary systems, not to mention the concrete containment vessel, instrumentation and control, and other support facilities. Over the initial forty-year lifetime of a LWR, internal structural components may expect to see up $\sim 10^{22} \mathrm{n} / \mathrm{cm}^{2}$ in a Boiling Water Reactor (BWR) and $\sim 10^{23} \mathrm{n} / \mathrm{cm}^{2}$ in a Pressurized Water Reactor (PWR) (E $>1 \mathrm{MeV}$ ), corresponding to $\sim 7 \mathrm{dpa}$ and $70 \mathrm{dpa}$, respectively. The neutron irradiation field can produce large property and dimensional changes in materials. Such changes occur primarily via five radiation damage processes: radiation-induced hardening and embrittlement, phase instabilities from radiation-induced or radiation-enhanced segregation and precipitation, irradiation creep, volumetric swelling from cavity formation, and high temperature helium embrittlement due to formation of helium-filled cavities on grain boundaries. Extending the service life of a reactor will increase neutron fluence and suscepti- 
Table 1. Summary of desired parameters for detection during fuel irradiation tests

\begin{tabular}{|c|c|c|c|}
\hline \multirow{2}{*}{ Parameter } & \multirow{2}{*}{ Representative Peak Value $^{\mathrm{a}}$} & \multicolumn{2}{|c|}{ Desired $^{\mathrm{a}}$} \\
\hline & & Accuracy & Spatial Resolution \\
\hline \multirow[t]{4}{*}{ fuel temperature } & Ceramic LWR $-1400^{\circ} \mathrm{C}$ & \multirow[t]{4}{*}{$2 \%$} & \multirow{4}{*}{$\begin{array}{l}1-2 \mathrm{~cm} \text { (axially) } \\
0.5 \mathrm{~cm} \text { (radially) }\end{array}$} \\
\hline & Ceramic SFR $-2600^{\circ} \mathrm{C}$ & & \\
\hline & Metallic SFR $-1100^{\circ} \mathrm{C}$ & & \\
\hline & TRISO HTGR - $1250{ }^{\circ} \mathrm{C}$ & & \\
\hline \multirow[t]{4}{*}{ cladding temperature } & Ceramic LWR - <400 ${ }^{\circ} \mathrm{C}$ & \multirow[t]{3}{*}{$2 \%$} & \multirow[t]{3}{*}{$1-2 \mathrm{~cm}$ (axially) } \\
\hline & Ceramic SFR - $650^{\circ} \mathrm{C}$ & & \\
\hline & Metallic SFR - $650^{\circ} \mathrm{C}$ & & \\
\hline & TRISO GCFR & NA & NA \\
\hline \multirow[t]{4}{*}{ pressure in fuel rod plenum } & Ceramic LWR - 5.5 MPa & \multirow[t]{4}{*}{$5 \%$} & \multirow[t]{4}{*}{$N A^{b}$} \\
\hline & Ceramic SFR - 8.6 MPa & & \\
\hline & Metallic SFR - 8.6 MPa & & \\
\hline & HTGR - NA & & \\
\hline $\begin{array}{l}\text { LWR, SFR, and HTGR fission gas } \\
\text { release (amount and composition) }\end{array}$ & $0-100 \%$ of inventory & $10 \%$ & NA \\
\hline \multirow{3}{*}{$\begin{array}{l}\text { LWR and SFR fuel and cladding } \\
\text { dimensions (includes fuel / cladding } \\
\text { gap size); HTGR-NA }\end{array}$} & Initial Length, $1 \mathrm{~cm}$ & $1 \%$ & NA \\
\hline & Outer diameter/Strain, $0.5 \mathrm{~cm} / 5-10 \%$ & $0.1 \%$ & NA \\
\hline & Fuel-Cladding Gap $(0-0.1 \mathrm{~mm})$ & $0.1 \%$ & NA \\
\hline \multirow{3}{*}{$\begin{array}{l}\text { LWR, SFR, and HTGR fuel } \\
\text { morphology/microstructure/ } \\
\text { cracking/ constituent redistribution }\end{array}$} & Grain size, $10 \mu \mathrm{m}$ & $5 \%$ & $1-10 \mu \mathrm{m}$ \\
\hline & Swelling/Porosity, 5-20\% & $2 \%$ & NA \\
\hline & Crack formation and growth & $2 \%$ & $10-100 \mu \mathrm{m}$ \\
\hline \multirow[t]{2}{*}{ fuel thermal properties } & $\begin{array}{c}\text { Thermal conductivity } \\
\text { Ceramic: }<8 \mathrm{~W} / \mathrm{mK} \text {; Metallic: }<50 \mathrm{~W} / \mathrm{mK} \text {; } \\
\text { TRISO pebble/compact: } 4-12 \mathrm{~W} / \mathrm{mK}\end{array}$ & $4 \%$ & $<1 \mathrm{~cm}$ (radially) \\
\hline & $\begin{array}{l}\text { Density (inferred from changes in length, diameter, } \\
\text { porosity, etc.) } \\
\text { Ceramic: }<11 \mathrm{~g} / \mathrm{cm}^{3} ; \text { Metallic: }<50 \mathrm{~g} / \mathrm{cm}^{3} \\
\text { TRISO pebble } / \mathrm{compact}^{3} 2.25 \mathrm{~g} / \mathrm{cm}^{3 \mathrm{c}}\end{array}$ & $2 \%$ & NA \\
\hline \multirow{2}{*}{$\begin{array}{l}\text { real-time thermal and fast neutron } \\
\text { flux for estimating fluence and fuel } \\
\text { burnup for fuel irradiations }\end{array}$} & Thermal neutron flux $-\sim 1-5 \times 10^{14} \mathrm{n} / \mathrm{cm}^{2}-\mathrm{s}$ & $1-10 \%$ & $5 \mathrm{~cm}$ (axially) \\
\hline & Fast neutron flux $(\mathrm{E}>1 \mathrm{MeV})-\sim 1-5 \times 10^{14} \mathrm{n} / \mathrm{cm}^{2}-\mathrm{s}$ & $15 \%$ & $5 \mathrm{~cm}$ (axially) \\
\hline
\end{tabular}

a. Representative peak values, accuracy, and resolution are based on engineering judgement by cognizant program experts.

b. NA-Not Applicable.

c. Value dependent upon particle packing fraction and matrix.

bility to radiation damage (although new damage mechanisms are possible). Likewise, when one considers the additional conditions proposed within DOE-NE programs for NGNP and Sodium Fast Reactor (SFR) operation, material performance becomes more complex.

Currently, most material irradiations are relying on Post Irradiation Examination (PIE) to characterize material properties after an irradiation is completed. However, enhanced in-pile instrumentation offers the potential to supplement current PIE evaluations by increased accuracy, higher fidelity data since measurements are obtained at the conditions of interest. Currently-requested accuracies and resolutions for these materials are listed in Table 2. 
Table 2. Summary of desired parameters for detection during materials irradiation tests

\begin{tabular}{|c|c|c|c|}
\hline \multirow[b]{2}{*}{ Parameter } & \multirow[b]{2}{*}{ Representative Peak Values $^{\mathrm{a}, \mathrm{b}}$} & \multicolumn{2}{|c|}{ Desired $^{\text {a,b }}$} \\
\hline & & Accuracy & $\begin{array}{c}\text { Spatial } \\
\text { Resolution }\end{array}$ \\
\hline \multirow[t]{4}{*}{ Material temperature distribution } & LWRS Fuel Cladding - $>1200^{\circ} \mathrm{C}$ & \multirow[t]{3}{*}{$2 \%$} & \multirow{3}{*}{$\begin{array}{l}1-2 \mathrm{~cm} \text { (axially); } \\
0.5 \mathrm{~cm} \text { (radially) }\end{array}$} \\
\hline & LWRS Vessel and Internal Materials $-500{ }^{\circ} \mathrm{C}$ & & \\
\hline & HTGR and LWRS high temperature alloys $-950{ }^{\circ} \mathrm{C}$ & & \\
\hline & HTGR Graphite -600 to $1200^{\circ} \mathrm{C}$ & $\begin{array}{l} \pm 50^{\circ} \mathrm{C} \text { (axially) } \\
\pm 40^{\circ} \mathrm{C} \text { (radially) }\end{array}$ & NA \\
\hline \multirow[t]{2}{*}{$\begin{array}{l}\text { Material dimensional changes due to } \\
\text { swelling }\end{array}$} & $\begin{array}{l}\text { Initial Specimen Length, } \\
\text { HTGR Graphite }-2.54 \mathrm{~cm}\end{array}$ & $1 \%$ & NA \\
\hline & $\begin{array}{c}\text { Outer diameter/Strain, } \\
\text { LWR vessel and internal materials }-0.5 \mathrm{~cm} / 5-10 \%\end{array}$ & $0.1 \%$ & NA \\
\hline \multirow{3}{*}{$\begin{array}{l}\text { Material morphology/ } \\
\text { microstructure/cracking/ constituent } \\
\text { redistribution }\end{array}$} & $\begin{array}{c}\text { Grain size, } \\
\text { LWR vessel and internal materials }>10 \mu \mathrm{m}\end{array}$ & $5 \%$ & $1-10 \mu \mathrm{m}$ \\
\hline & $\begin{array}{c}\text { Swelling/Porosity, } \\
\text { LWR vessel and internal materials 5-20\% }\end{array}$ & $2 \%$ & $10-100 \mu \mathrm{m}$ \\
\hline & $\begin{array}{l}\text { Crack formation and growth } \\
\text { LWR vessel and internal materials }>10 \mu \mathrm{m}\end{array}$ & $2 \%$ & $10-100 \mu \mathrm{m}$ \\
\hline \multirow[t]{4}{*}{ Material thermal properties } & $\begin{array}{l}\text { Thermal conductivity } \\
\text { HTGR Graphite - } 80 \mathrm{~W} / \mathrm{m}-\mathrm{K}\end{array}$ & $4 \%$ & $<1 \mathrm{~cm}$ (radially) \\
\hline & $\begin{array}{l}\text { Thermal conductivity } \\
\text { LWR vessel and internal materials } \sim 50 \mathrm{~W} / \mathrm{m}-\mathrm{K}\end{array}$ & $5-20 \%$ & $<1 \mathrm{~cm}$ \\
\hline & $\begin{array}{l}\text { Thermal coefficient of expansion; } \\
\text { HTGR Graphite - } 5 \%\end{array}$ & $2 \%$ & $\mathrm{NA}^{\mathrm{c}}$ \\
\hline & $\begin{array}{c}\text { Density (estimated from changes in length, diameter, } \\
\text { porosity, etc.) } \\
\text { HTGR Graphite }-0.5 \%\end{array}$ & $0.2 \%$ & NA \\
\hline \multirow[t]{5}{*}{$\begin{array}{c}\text { Material mechanical/electrical } \\
\text { properties }\end{array}$} & $\begin{array}{c}\text { Irradiation creep } \\
\text { HTGR Graphite - 3-4\% }\end{array}$ & NA & NA \\
\hline & $\begin{array}{l}\text { Young's modulus } \\
\text { HTGR Graphite - 3-4\% }\end{array}$ & NA & NA \\
\hline & $\begin{array}{c}\text { Electrical resistivity } \\
\text { HTGR Graphite - 3-4\% }\end{array}$ & NA & NA \\
\hline & $\begin{array}{c}\text { Poisson's ratio } \\
\text { HTGR Graphite - 3-4\% }\end{array}$ & NA & NA \\
\hline & $\begin{array}{c}\text { Fracture toughness, shear strength } \\
\text { HTGR Graphite - 3-4\% }\end{array}$ & NA & NA \\
\hline \multirow{2}{*}{$\begin{array}{l}\text { Material irradiation neutron flux for } \\
\text { estimating fluence }\end{array}$} & Thermal neutron flux $-\sim 1-5 \times 10^{14} \mathrm{n} / \mathrm{cm}^{2}-\mathrm{s}$ & $1-10 \%$ & $5 \mathrm{~cm}$ (axially) \\
\hline & Fast neutron flux $(\mathrm{E}>1 \mathrm{MeV})-\sim 1-5 \times 10^{14} \mathrm{n} / \mathrm{cm}^{2}-\mathrm{s}$ & $15 \%$ & $5 \mathrm{~cm}$ (axially) \\
\hline
\end{tabular}

a. Representative peak values, accuracy, and resolution are based on engineering judgement and are preliminary.

b. Only LWRS and NGNP irradiation information available for a limited number of parameters at this time.

c. NA-Not Available. 


\section{BACKGROUND}

This section describes commonly used flux detection sensors in typical MTR irradiations. A brief overview discussing their theory of operation, basic construction, deployment considerations, data collection considerations, and basic advantages/disadvantages is given to emphasize advantages of the HT MPFDs and how they uniquely address irradiation testing needs for DOE-NE programs.

\subsection{Flux Sensors}

Accurate measurement of the time-dependent neutron field, the neutron flux, and the integral exposure or the neutron fluence that a sample receives is needed in order to assess effects of neutron interactions on the samples under investigation. Some tests only require that the overall neutron fluence be known. Hence, passive methods are used to measure the neutron irradiation after the sample has been removed from the reactor. Many DOE-NE irradiation tests rely on passive neutron fluence measurement techniques. However, as discussed in Section 1, many DOE-NE programs have identified candidate new materials and fuels whose performance evaluations require high accuracy/high resolution real-time fast and thermal flux measurements. Such measurements are typically accomplished with Self-Powered Neutron Detectors (SPNDs) or fission chambers. As indicated in Table 3, there are advantages and disadvantages with each type of detector. ${ }^{5 \text { through }} 7$ This section describes typical examples of each type of sensor along with their limitations in irradiation tests to emphasize the need for this project to develop HT MPFDs for use in DOE-NE irradiation test programs in higher flux US MTRs, such as the $250 \mathrm{MWt}$ Advanced Test Reactor (ATR) and the $100 \mathrm{MWt}$ High Flux Isotope Reactor (HFIR) and the Transient REActor Test (TREAT) reactor.

Table 3. Summary of advantages and disadvantages of typical flux sensors

\begin{tabular}{|c|c|c|c|}
\hline \multirow{2}{*}{ Flux Sensor } & \multirow{2}{*}{ General description } & \multicolumn{2}{|c|}{ Typical characteristics } \\
\hline & & Advantages & \begin{tabular}{|c|} 
Disadvantages \\
\end{tabular} \\
\hline $\begin{array}{c}\text { Flux Wires and } \\
\text { Foils }\end{array}$ & $\begin{array}{l}\text { Utilizes neutron activation of } \\
\text { materials to emit measurable } \\
\text { gamma-rays }\end{array}$ & $\begin{array}{l}\text { Small } \\
\text { Thermal/Fast neutron response } \\
\text { No power source } \\
\text { Simple/robust } \\
\text { Easily installed }\end{array}$ & $\begin{array}{l}\text { Not real time } \\
\text { Rigorous post-analysis } \\
\text { Integral measurement }\end{array}$ \\
\hline $\begin{array}{l}\text { Self Powered } \\
\text { Neutron } \\
\text { Detectors }\end{array}$ & $\begin{array}{l}\text { Generates measurable } \\
\text { electrical current under } \\
\text { neutron irradiation }\end{array}$ & $\begin{array}{l}\text { Real time } \\
\text { Small } \\
\text { Thermal neutron response } \\
\text { No power source } \\
\text { Simple/robust }\end{array}$ & $\begin{array}{l}\text { Need calibration } \\
\text { No fast neutron response } \\
\text { Low sensitivity } \\
\text { Delayed response } \\
\text { Need electrometer }\end{array}$ \\
\hline $\begin{array}{c}\text { Fission } \\
\text { Chambers }\end{array}$ & $\begin{array}{l}\text { Fissionable material } \\
\text { interactions provide } \\
\text { measurable electrical pulses }\end{array}$ & \begin{tabular}{|l} 
Real time \\
Small \\
Thermal/fast neutron response \\
Variable sensitivity
\end{tabular} & $\begin{array}{l}\text { Need power source } \\
\text { Fragile }\end{array}$ \\
\hline $\begin{array}{c}\text { Micro-Pocket } \\
\text { Fission Detectors }\end{array}$ & $\begin{array}{l}\text { Fissionable material } \\
\text { interactions provide } \\
\text { measurable electrical pulses }\end{array}$ & $\begin{array}{l}\text { Real time } \\
\text { Small } \\
\text { Simple/robust } \\
\text { Simultaneous thermal/fast neutron } \\
\text { response with temperature } \\
\text { measurement } \\
\text { Variable sensitivity } \\
\text { Low power requirements }\end{array}$ & Need power source \\
\hline
\end{tabular}




\subsubsection{Flux Wires and Foils}

Flux wires and foils are the most commonly used passive methods for local neutron activation spectrometry. A flux wire or foil is simply a material of known composition and purity that is placed in a neutron field. When placed in a neutron field, different elements (and different isotopes of the same element) interact differently with respect to the energy of the incident neutron. When the interaction product is radioactive, the resulting induced activity can be measured and correlated to the integral incident neutron exposure. ${ }^{5}$ This measurement and correlation can only be performed after the irradiation is complete and the flux wire or foil is removed from the reactor.

Deployment simply requires that the flux wires or foils be securely placed in the reactor in appropriate fixturing (Figure 1). Hence, they can be placed at nearly any location in the reactor. Some materials can be placed directly in contact with the reactor primary coolant, whereas other more fragile materials must be encased in low cross-section materials that don't affect their neutron exposure. Data collection requires removing the radioactive flux wires or foils from the reactor and placing them on a gamma ray detector and counting them for a specific amount of time. The counting information and material information, along with the irradiation time and the time since the end of the irradiation, can then be used to calculate the neutron flux. The advantages of this method are: very small sensors can be used; it is generally very accurate; it can be used for high and low flux levels; and it gives information about the incident neutron energy. The disadvantages are that it is not real-time and that it requires handling radioactive material.
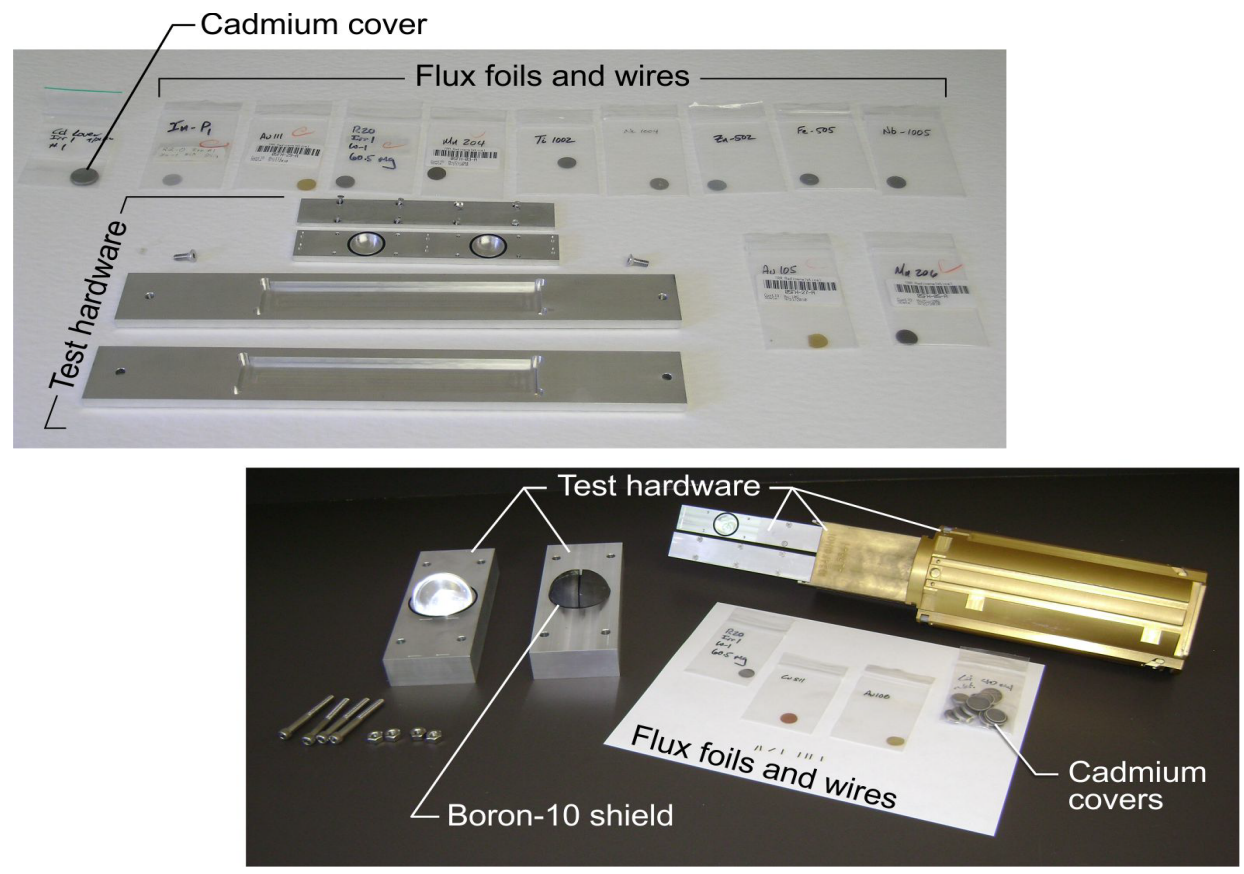

Figure 1. Representative flux wires, flux foils and test hardware used at INL 


\subsubsection{Self Powered Neutron Detectors}

SPNDs are a commonly used real-time method for monitoring local neutron flux. SPNDs are built using materials that become radioactive in a neutron field and produce a small current which is correlated to the neutron flux (Figure 2). SPNDs are built around a central electrode, known as an emitter, which is composed of a metal with a relatively high neutron capture cross section. ${ }^{5}$ Typical emitters and their properties are listed in Table 4. The central electrode is surrounded by an electrical insulator and an outer electrode, known as a collector. The outer electrode serves as a boundary between the reactor coolant and the emitter and insulator. The current between the emitter and collector is measured via external circuitry. It can take time for the current to build up in the SPND; hence, there is a delay time from several seconds to a few minutes before the signal is generated. In addition, if the neutron signal is suddenly changed it will take several minutes for the signal to stabilize.
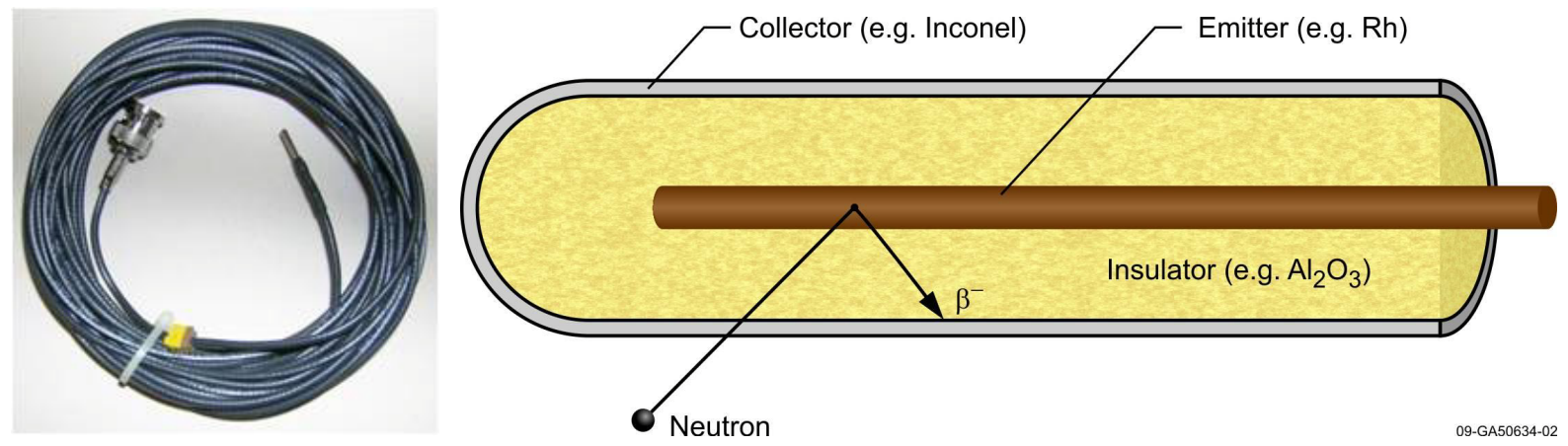

Figure 2. Representative Self-Powered Neutron Detector (SPND) and component sketch

Table 4. Typical emitters for SPNDs

\begin{tabular}{|c|c|c|}
\hline SPND Emitter & Sensitivity $(\mathbf{A} / \mathbf{m}) /\left[\mathbf{2} \times 10^{17}{\left.\text { neutrons } /\left(\mathbf{m}^{2} \mathbf{s}\right)\right]}^{-6}\right.$ & Response \\
\hline Rhodium & $2.4 \times 10^{-6}$ & Delayed \\
\hline Vanadium & $1.5 \times 10^{-7}$ & Delayed \\
\hline Cobalt & $3.4 \times 10^{-8}$ & Prompt \\
\hline Molybdenum & $1.7 \times 10^{-8}$ & Prompt \\
\hline Platinum & $2.6 \times 10^{-7}$ & Prompt \\
\hline
\end{tabular}

Deployment requires a space large enough to fit the SPND, typically 1.5-6 $\mathrm{mm}$ in diameter, and the leads to be run from the experiment location to outside the reactor for signal processing; hence, SPNDs can only be deployed in specific experiment locations in the reactor. Data collection requires the SPNDs to be connected to sensitive low current measurement equipment. The SPNDs must be previously calibrated in a known neutron field so that the current response can be correlated to the incident neutron flux. The advantages of this method include: it is self powered; it provides near real time neutron flux measurement; and it is a robust sensor. The disadvantages include: it has delays associated with its response; it requires a large neutron flux to generate a large current; it requires a calibration; it is generally limited to thermal neutrons; and it requires signal leads from the experiment to outside the reactor. ${ }^{5}$ 


\subsubsection{Fission Chambers}

Fission chambers are another commonly used real-time method for monitoring local neutron flux. As shown in Figure 3, fission chambers are built using two electrodes, one has a fissile material deposit that emits fission fragments when placed in a neutron field. These fission fragments produce an instantaneous current pulse between the electrodes that have a polarization voltage applied between them. The resulting pulse is measured via external counting electronics. The space between the electrodes must have a fill gas to aid detector performance. Like SPNDs, the outer electrode serves as a boundary between the reactor coolant and the inner materials. The fissile material deposit can be chosen such that the detector is sensitive to either thermal neutrons or fast neutrons. Fission chambers can be operated in three different modes: pulse mode for low power applications that measure the individual pulses, current mode for midrange power applications where pulses are so frequent that they can't be separated and produce a continuous current, and Campbelling mode for high power applications where the variance of the signal is characterized and correlated to the incident neutron flux. ${ }^{5}$
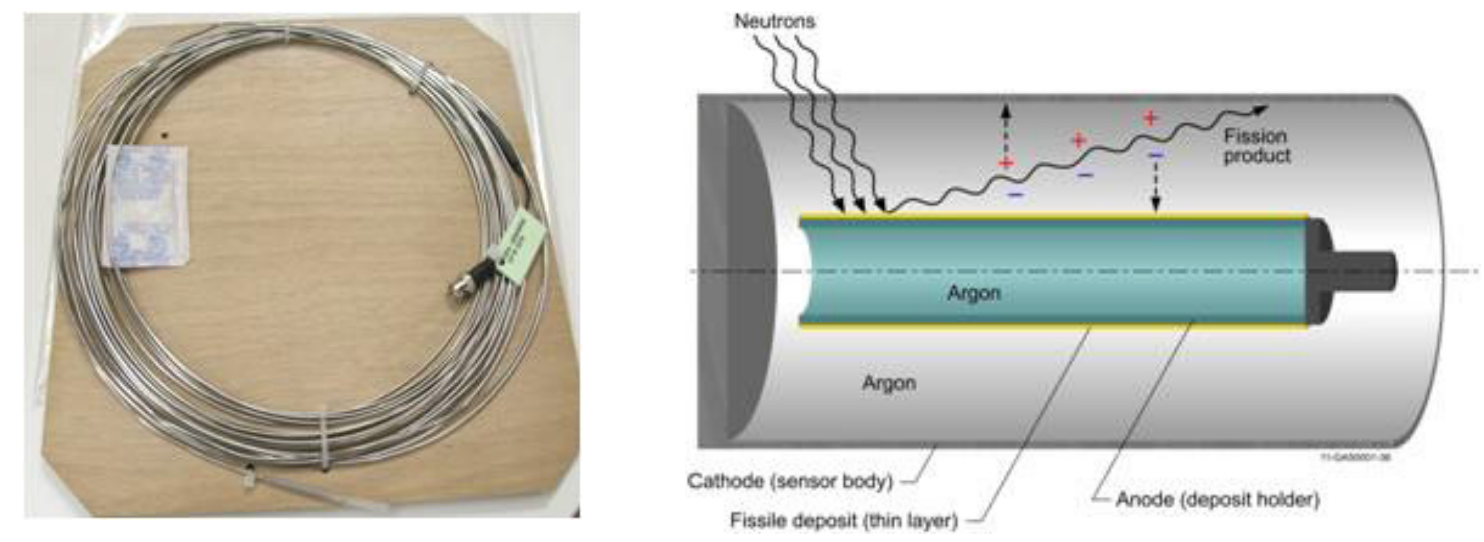

Figure 3. Representative fission chamber and component sketch

Deployment requires a space large enough to fit the fission chambers, typically $1.5-150 \mathrm{~mm}$ diameter, and leads from the fission chamber location to outside the reactor vessel for data display and storage. Hence, fission chambers can only be deployed in specific experiment locations in the reactor and sometimes are deployed outside the reactor core for large fission chambers or to improve fission chamber lifetime. Fission chamber response is correlated to incident neutron flux by accurate measurement of the fissionable deposit mass or by prior calibration in a neutron field. The advantages of this method include: it is real-time; it can be used for small and large neutron fluxes; it can be designed for thermal and fast neutron flux measurements; and it is more accurate then SPNDs. ${ }^{5}$ The disadvantages include: it is more delicate; it can require a larger space in the reactor; and it requires signal leads from the experiment to outside the reactor.

\subsubsection{Miniature and Sub-Miniature Fission Chambers}

Irradiations at US MTRs are typically performed at high fluxes using small samples with limited space for instrumentation. In addition, some DOE-NE irradiations must be performed at high temperatures (up to $2600{ }^{\circ} \mathrm{C}$ ). Fission chambers must be sufficiently robust to survive these harsh conditions for the length of 
the experiment. As such, special fission chambers have been developed or are under development for use in US MTR experiments. The following section discusses several of these in-core fission chambers deemed most promising.

The Commissariat à l'Énergie Atomique et aux Energies Alternatives (CEA) has over 40 years of experience in design, construction and use of miniature and sub-miniature fission chambers for MTR experiments (Figure 4). ${ }^{6,7}$ CEA-developed fission chambers are as small as $1.5 \mathrm{~mm}$ diameter for sub-miniature fission chambers and $3 \mathrm{~mm}$ diameter for miniature fission chambers. The designs utilize two coaxial cylindrical electrodes of which the center electrode is covered with fissile material. The area between the electrodes is filled with argon gas between 1-10 atm pressure. The complexity of the coaxial design along with the potential for the high pressure fill gas to leak makes these miniature fission chambers more susceptible to damage during harsh irradiations. ${ }^{6,7}$ The CEA fission chamber sensitivity to thermal and fast neutrons is increased by using different fissile material deposits. In addition, as part of the Joint Instrumentation Laboratory, CEA and Studiecentrum vor Kernenergie Centre d'Étude de l'Énergie Nucléaire(SCK•CEN) have also developed a Fast Neutron Detector System (FNDS) for monitoring fast neutron flux in large flux environments. Prior to the development of a new type of fission chamber, CEA models the expected response with specially developed software. .,7 $^{-1}$
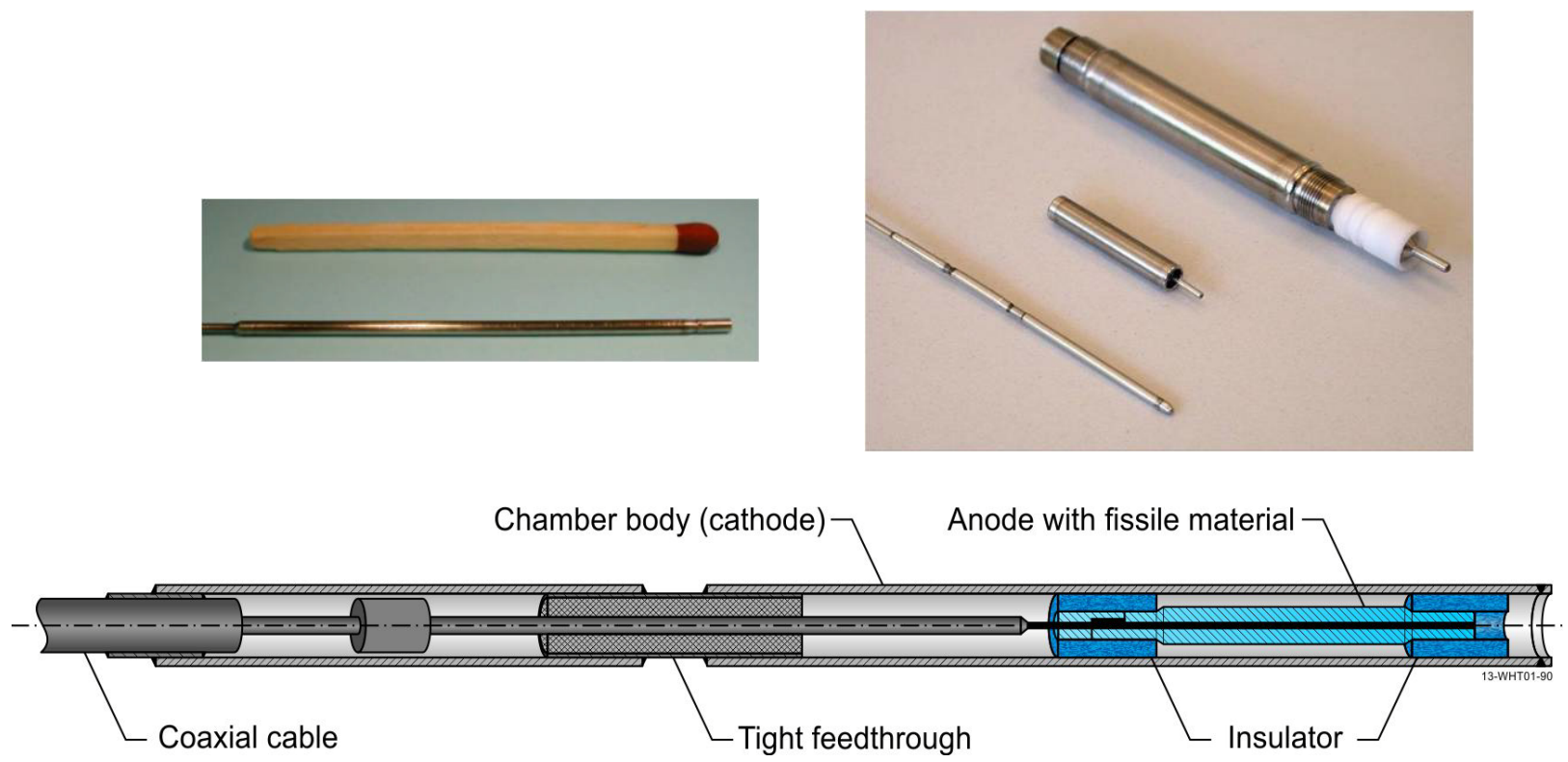

Figure 4. Representative CEA miniature fission chambers and component sketch

\subsubsection{Micro-Pocket Fission Detector Technology}

Within the last decade, efforts were initiated by the Kansas State University (KSU) to develop the MPFD technology that has the potential to simultaneously detect thermal and fast flux along with temperature in a single miniature sensor. ${ }^{8}$ through 13 Initial 'proof-of-concept' evaluations to demonstrate MPFD technology performance were completed at the KSU TRIGA reactor. However, prior to deployment of this new MPFD technology in a US MTR, a more robust sensor design was required. As discussed in Section 3, previous 
research conducted through NEET ASI ${ }^{1-3}$ has shown that the MPFD technology could be made robust and was successfully tested in a reactor core.

MPFD technology utilizes the same concept as coaxial fission chambers, but with a different geometry that uses parallel plate electrodes instead of coaxial cylinders. This design is known as a parallel plate fission chamber. However, the MPFD design is distinguished from other fission chambers because their signal is not based on the full energy deposition in the electrode gap from the fission products. This departure from conventional fission chamber design and operating characteristics allows the MPFD technology to have a much smaller chamber size with a much lower fill gas pressure. The MPFD design has excellent discrimination characteristics because the energy deposited by the fission products is much greater than other types of background radiation interactions in the detector. Another benefit is that the small size allows them to have a faster response time. Thus, the smaller MPFD design has the potential to achieve higher count rates then conventional fission chamber designs. The construction materials chosen for the MPFD technology includes temperature and radiation resistant ceramics. All of these characteristics make the MPFD technology well-suited to survive the harsh conditions present in DOE-NE MTR experiments. ${ }^{8}$ through 13 


\section{MPFD INVESTIGATIONS}

This section presents the scope for this NEET ASI project and summarizes investigation activities completed in this effort. A brief review of collaborator facilities and prior NEET ASI ${ }^{1-3}$ activities to develop the MPFD technology is also presented. In addition, a discussion of additional irradiation opportunities funded by other DOE-NE programs is included.

\subsection{Overall Plan and Schedule}

This joint INL/KSU/CEA project consists of seven tasks to be completed within three years. Figure 5 illustrates activities to be performed each year of this project and the organizations participating in each activity. Task 1 of this project is devoted to enhancing the previously developed MPFD design ${ }^{1-3}$ for higher temperature applications and procuring candidate materials. Task 2 activities included refining construction techniques to fabricate a HT MPFD. Task 3 will evaluate the HT MPFD in high temperature furnaces and autoclaves as well as develop computer based analysis models of the detector performance. Task 4 will focus on evaluations in available irradiation facilities. In Task 5, investigators will procure new materials and refine the HT MPFD design and construction methods as well as update analysis models as needed depending on Task 4 results. Task 6 will repeat Task 4 evaluations and compare and contrast design changes in actual and analytical evaluations. Task 7 includes all of the ongoing reporting and project management to manage subcontracts and prepare annual reports and publications.

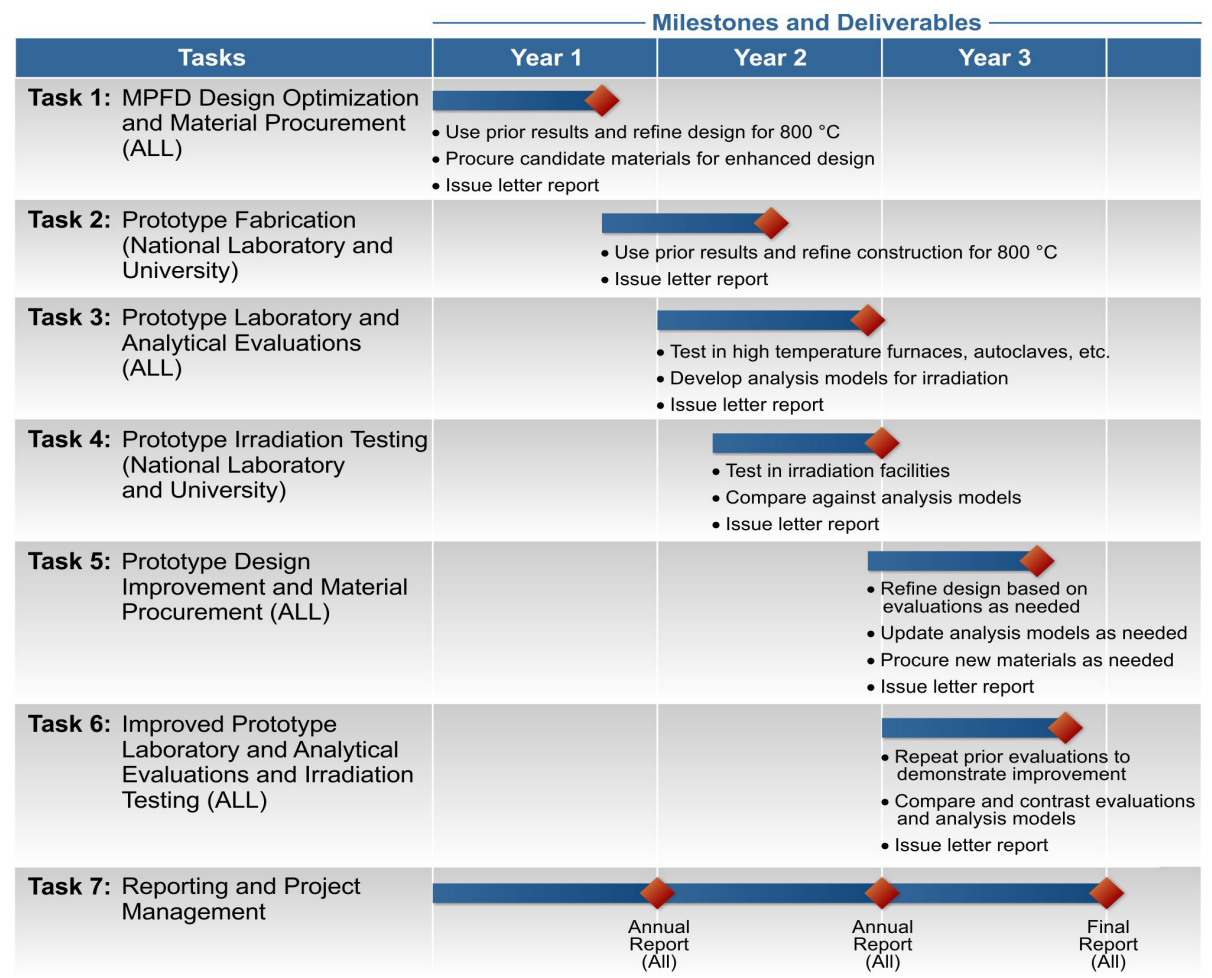

Figure 5. MPFD development tasks 


\subsection{Prior Activities and Collaborator Capabilities}

Research activities for previous development of the MPFD technology is discussed in the following sections. In addition, the capabilities of the collaborating organizations are summarized to provide a brief overview as why the research team was chosen.

\subsubsection{KSU MPFD Design and Evaluation Activities (Prior to Start of HT MPFD Project)}

Initial development of prototype KSU MPFD designs began at KSU using large ( $25 \mathrm{~mm}$ x $25 \mathrm{~mm})$ alumina substrates with deposited electrical contacts (Figure 6). ${ }^{8}$ through 13 Evaluations for depositing neutron reactive materials explored various methods, including boron with physical vapor deposition, uranyl nitrate solution with an eyedropper, and uranium and thorium coatings using electrolysis. After the neutron reactive material was applied, the detector substrates were bonded together using epoxy in an argon atmosphere. The first KSU MPFD prototypes were tested in a neutron beam at the KSU TRIGA research reactor with successful results. However, it was recognized that the manufacturing process was not ideal to produce detectors for in-core applications
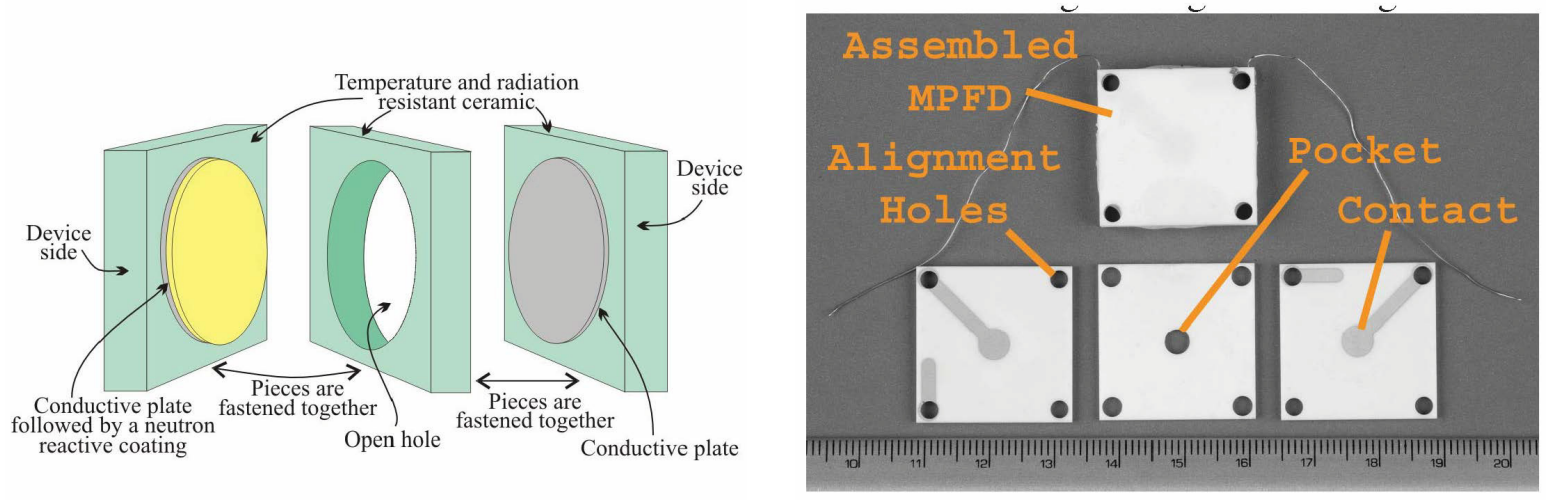

Figure 6. KSU MPFD component sketch (left) and initial KSU prototype MPFD (right)

Further refinements to the KSU MPFD design combined three chambers (one fast, one thermal, one background) and provided space for a thermocouple on a single substrate. Although the three chamber design incorporated multiple sensors in a single package, the new design was smaller ( $\sim 25 \mathrm{~mm}$ x $6 \mathrm{~mm})$ than previous designs. 8 through 13 Electroplating proved to be the most reliable method to deposit the neutron reactive materials. Uranium was used for thermal neutron detection, and thorium was used for fast neutron detection. The background chamber was added to demonstrate that the neutron sensitive chambers were insensitive to background radiation. The provision for a temperature measurement with a Type K thermocouple wire bonded to the detector substrate was included; however, the attachment method was not ideal for optimal thermocouple performance.

Deployment of KSU MPFDs in their TRIGA reactor had limited success. ${ }^{8}$ through 13 The testing resulted in the largest amount of the MPFD technology ever installed in a reactor core, 225 detectors. However, only about one third of them functioned; and the detectors that did function had issues with cross-talk between 
the output signals. The operational issues were due to water flooding into the probe tubes, wiring isolation issues, and improperly selected electronics. The probe tubes were constructed using three different diameters of aluminum tubes welded together using a TIG welder. The tubes were checked for leak tightness in a shallow water tank, but several tubes leaked when deployed in the KSU TRIGA reactor tank.

The wiring was required to exit the KSU designed MPFD perpendicular to the substrate and immediately make a 90 degree bend to travel inside a protective metal sheath. The wires were separated from each other using wire guides, but were not shielded from each other for their entire length. After deployment in the reactor, it was discovered that several of the wires were in contact with each other and the outer sheath, rendering many detectors unusable.

In addition, the KSU designed MPFDs utilized a single power source to reduce the amount of wires extending the length down to the reactor core. After deployment, it was determined that this arrangement introduced cross-talk issues that led to multiple pulses from a single detector that shared a power supply with other detectors. ${ }^{8}$ through 13

\subsubsection{NEET ASI MPFD Design and Evaluation Activities (Prior to Start of HT MPFD Project)}

The MPFD technology gained interest for further development during a 3 year project to refine previous MPFD designs for use in MTR irradiations. A NEET ASI project, Micro-Pocket Fission Detector, was awarded in 2012 to develop a MPFD design suitable for use in these harsh irradiation conditions. ${ }^{1-3}$

This MPFD design for MTR irradiations uses a round stackable geometry (Figure 7). The round design characteristic solves three problems associated with the previous KSU design. First, a round geometry is more suitable for installation in leak-tight swaged, drawn, or loose assembly tubes, eliminating water ingress problems. Second, the round tube geometry includes insulation for the wires along their entire length from the reactor core to the data acquisition system, eliminating the potential for wire-to-wire contact. Third, the wire connections are made through the detector substrate, eliminating a 90 degree wire bend used in the original KSU MPFD design (Figure 8).

It was also determined that the third chamber used for detection of background radiation was unnecessary because prior KSU testing demonstrated the MPFD design is background insensitive due to the small size. An additional benefit of the stackable design is the potential for multiple detectors of varying sensitivities to be added as customer requirements dictate. The thermocouple is placed directly above the fission chambers in the loose assembly (Figure 9). This eliminates the additional wire bonding required in the KSU design, thus improving thermocouple performance and robustness. In addition, an INL invention disclosure record was filled on the MPFD technology. ${ }^{14}$

While undergoing construction, the construction methods were assessed by considering thermocouple response, x-ray observations, helium leak checks, and resistance and continuity measurements. The material deposition was carefully monitored to produce robust electrical contacts and fissile material deposits. Sheath and weld integrity was evaluated using helium leak testing equipment to verify that the assembly meets requirements for the ASTM leak rate of sheathed thermocouples. ${ }^{15}$ Leak testing revealed that the round geometry MFPD leak rates were well below ASTM thermocouple leak rate limits. 


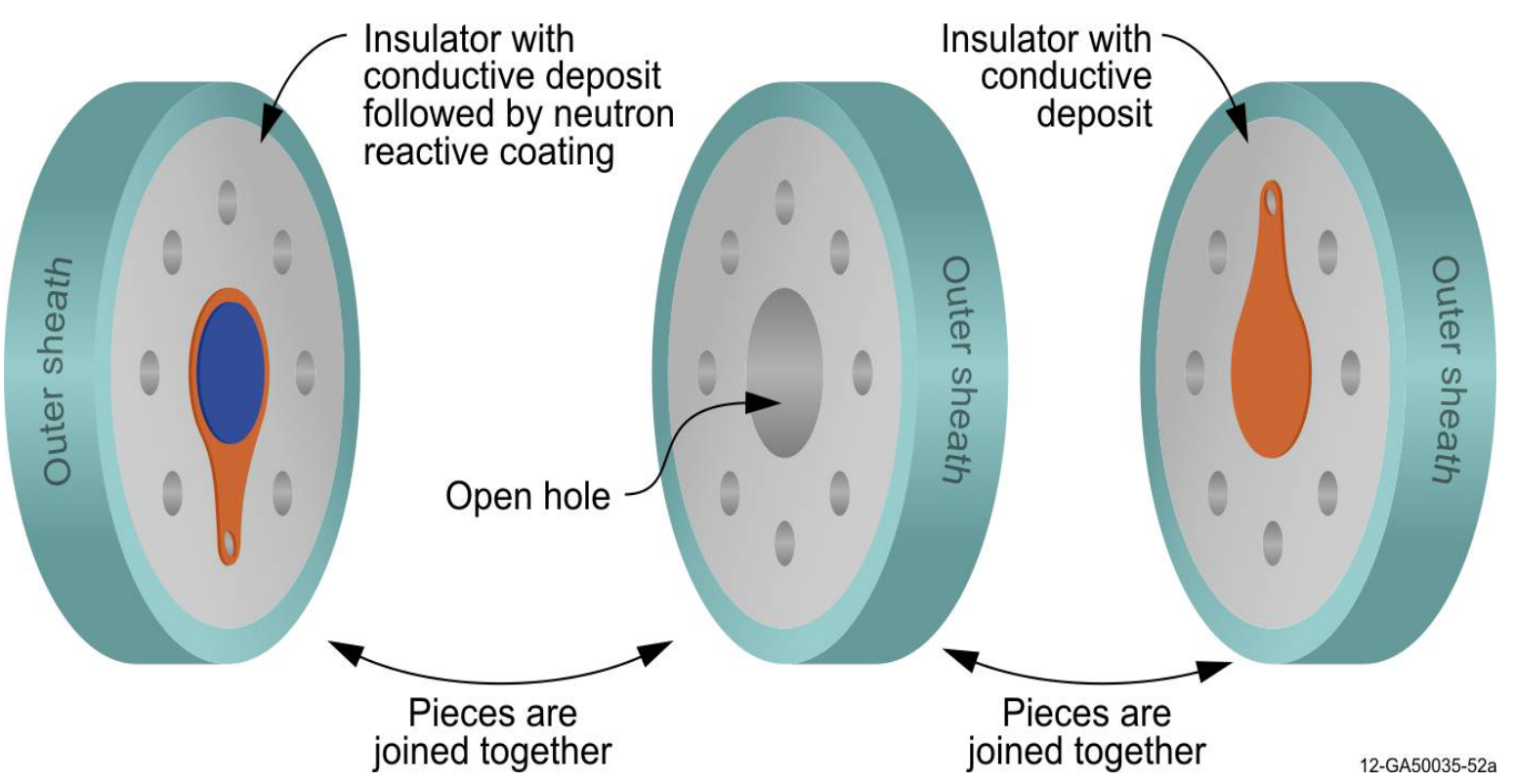

Figure 7. Round geometry MPFD design suitable for MTR irradiations

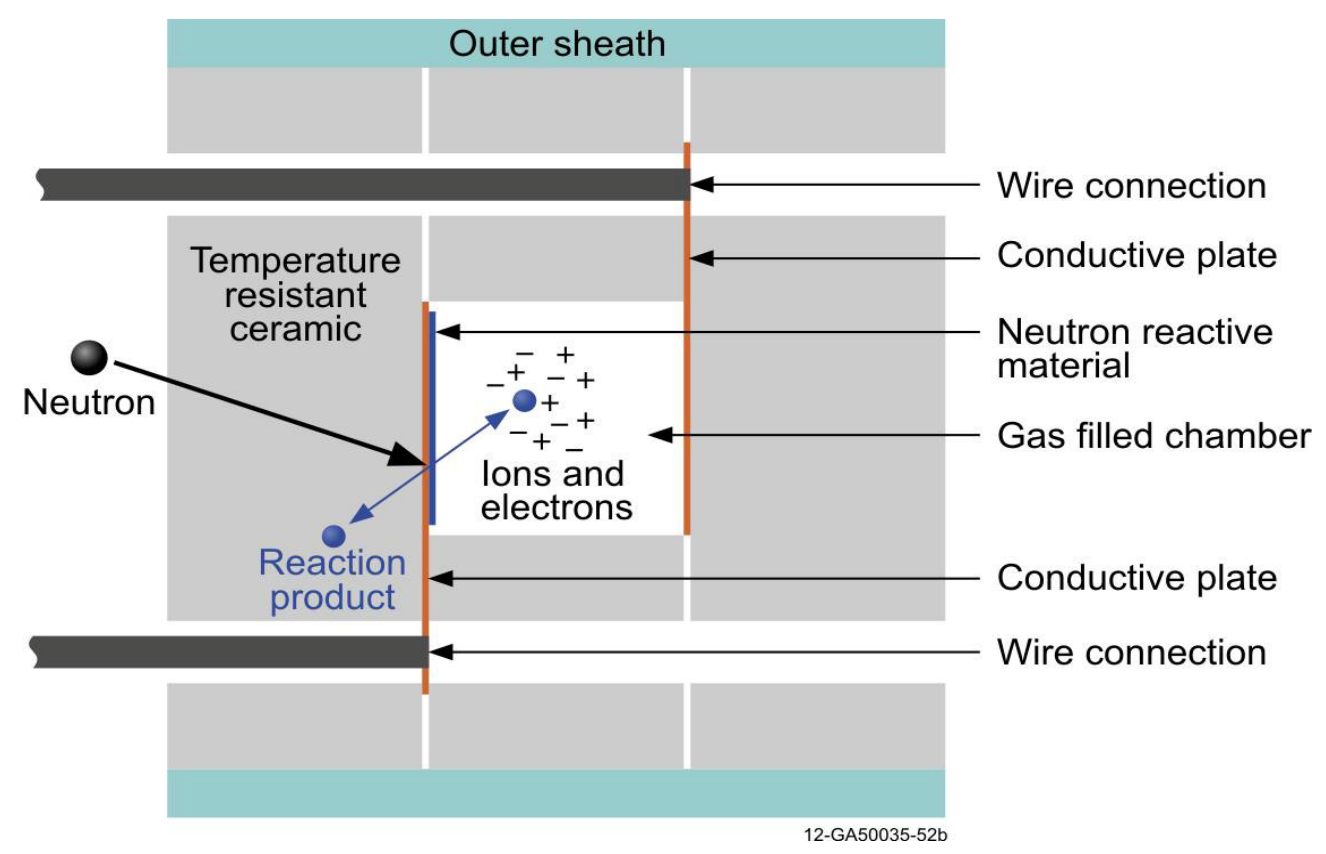

Figure 8. Component diagram of MPFD design showing wire locations

After an acceptable leak rate was verified, external wiring was added to allow the round-geometry MPFDs to be connected to a data acquisition system (Figure 11) for long duration tests in a high temperature furnace. These evaluations were performed in furnaces to verify the internal wiring connections and thermocouple performance would survive at $500{ }^{\circ} \mathrm{C}$ for 1000 continuous hours. The evaluations indicated the wiring connections and thermocouple performance could survive at these elevated temperature for more than 1000 hours. As shown in Figure 12, the thermocouple inside this design of MPFD continued to provide a temperature reading consistent with the Type $\mathrm{K}$ reference thermocouple included in this test. Like- 


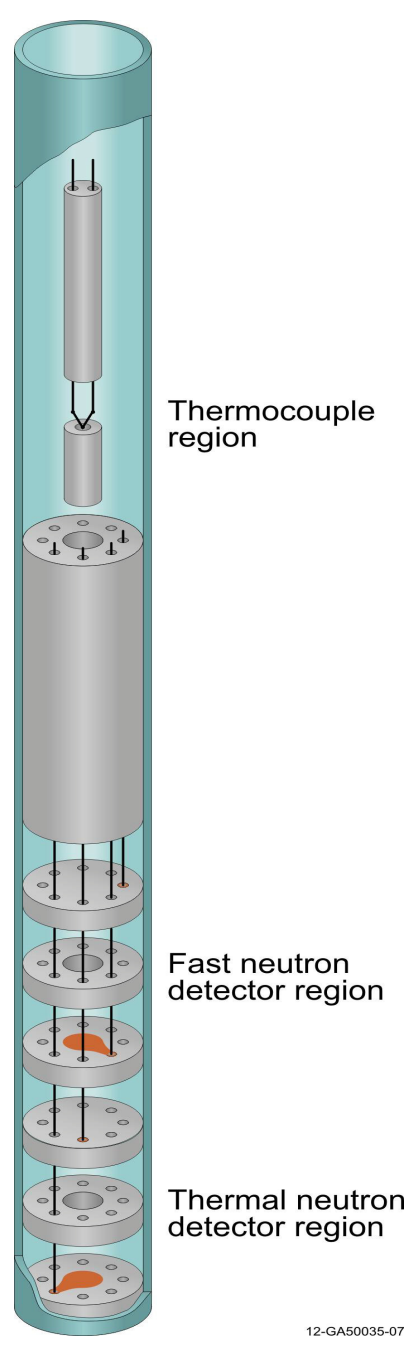

Figure 9. Initial MPFD design for MTR irradiations

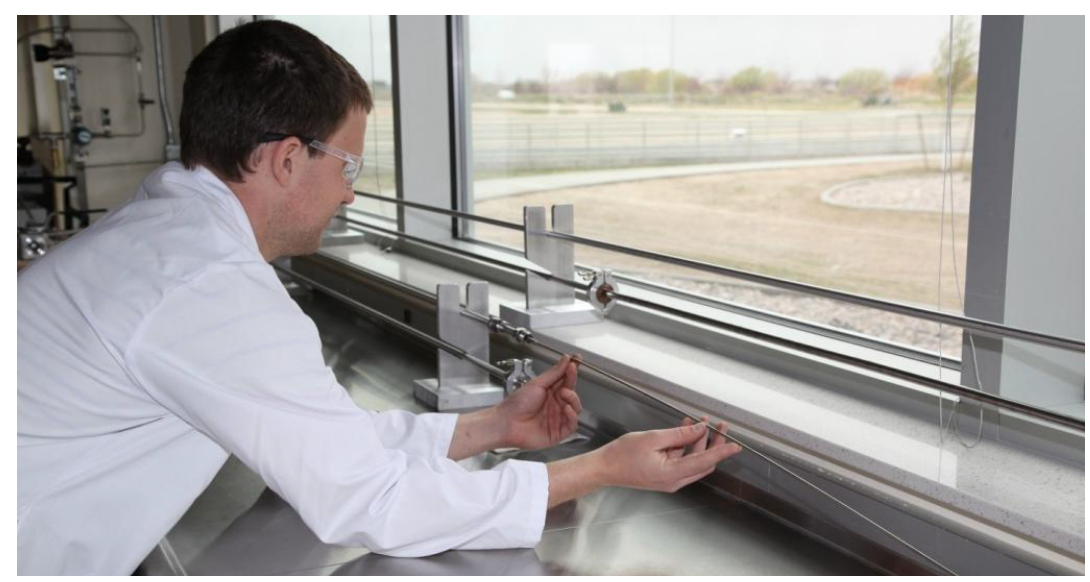

Figure 10. Leak testing an enhanced MPFD in specialized HTTL leak detection system 
wise, connections to flux detector components survived as indicated by their continuous and consistent voltage signal throughout the test.
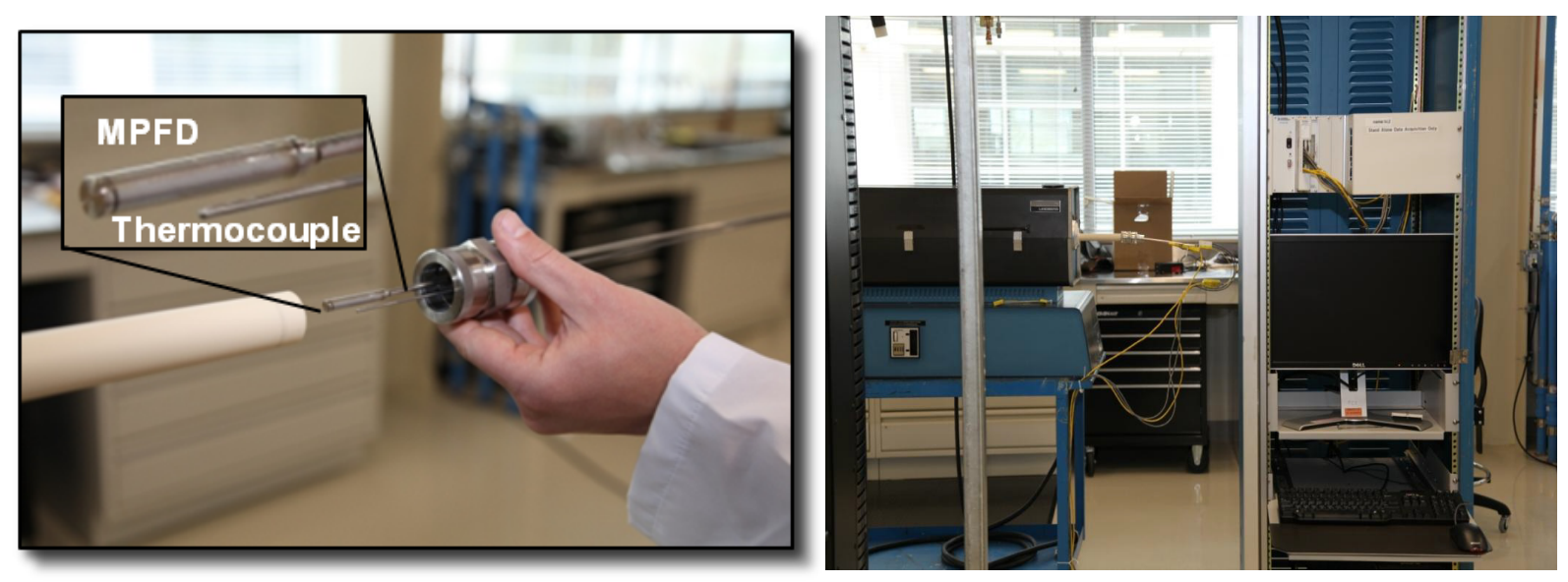

Figure 11. Round geometry MPFD installation into furnace and data acquisition system

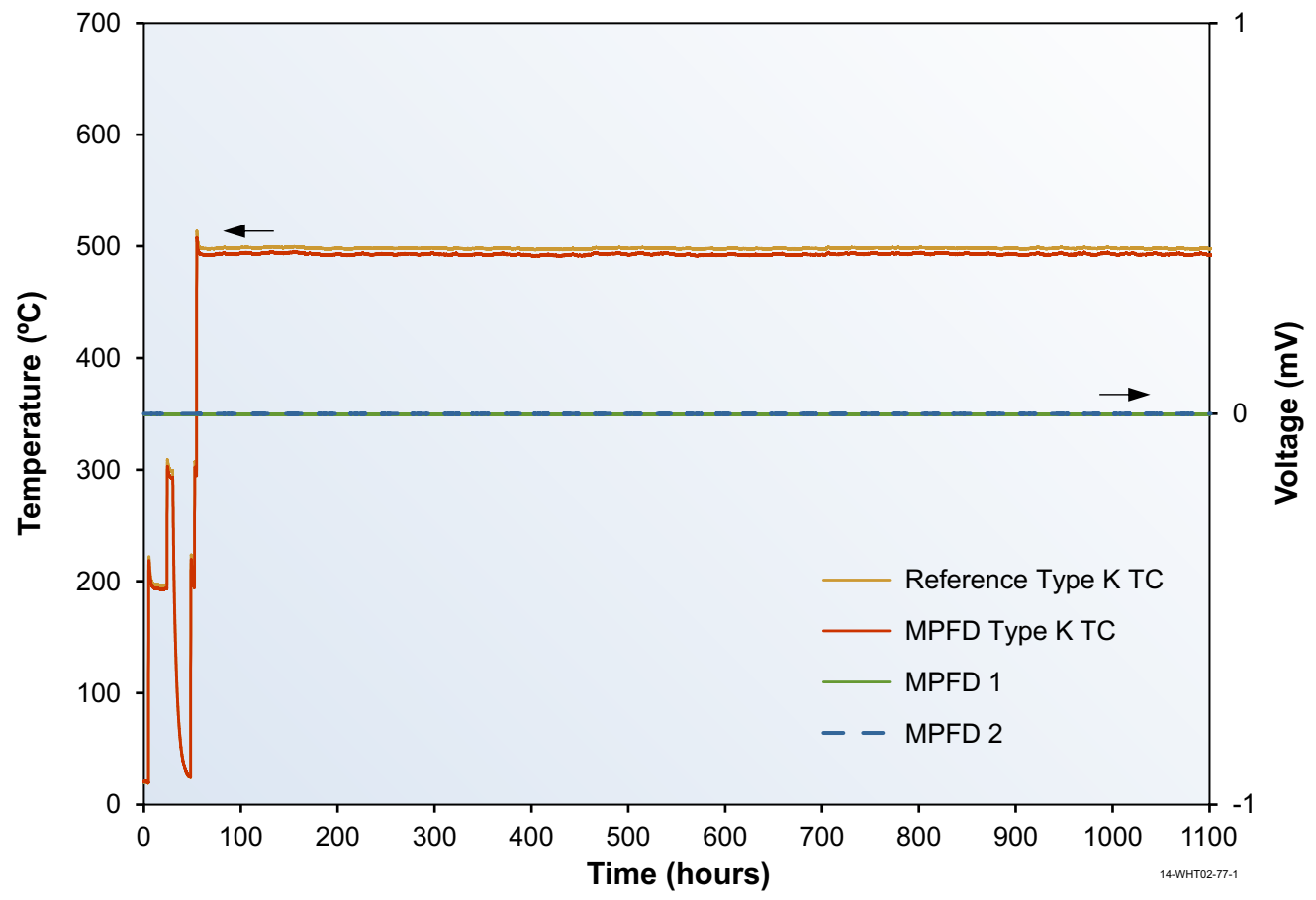

Figure 12. Round geometry MPFD long duration high temperature test results

Radiation sensitivity testing was performed at the KSU TRIGA reactor by installing the round geometry MPFDs in the central thimble of the reactor core (see Figure 13) using the specially developed signal amplifiers. The round geometry MPFDs were tested in-core at thermal and fast fluxes of $2.00 \times 10^{13} \mathrm{n} /$ $\mathrm{cm}^{2}$-s and $2.00 \times 10^{14} \mathrm{n} / \mathrm{cm}^{2}$-s, respectively. Typical detector pulses are shown in Figure 14. 


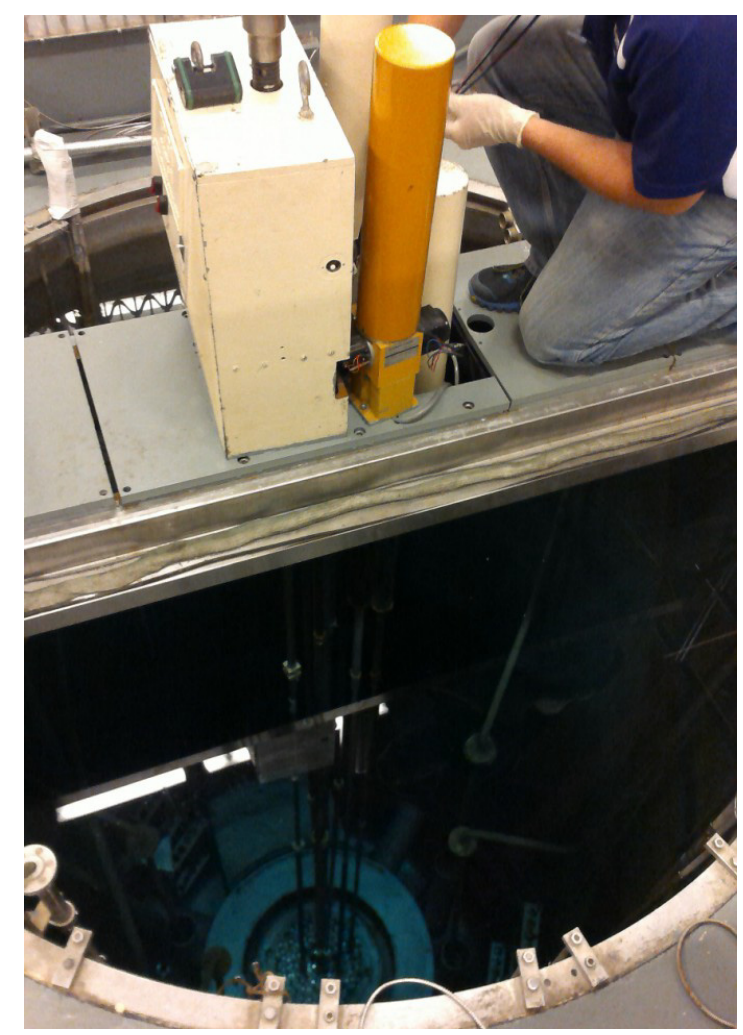

Figure 13. MPFD installation in the central thimble at KSU TRIGA reactor

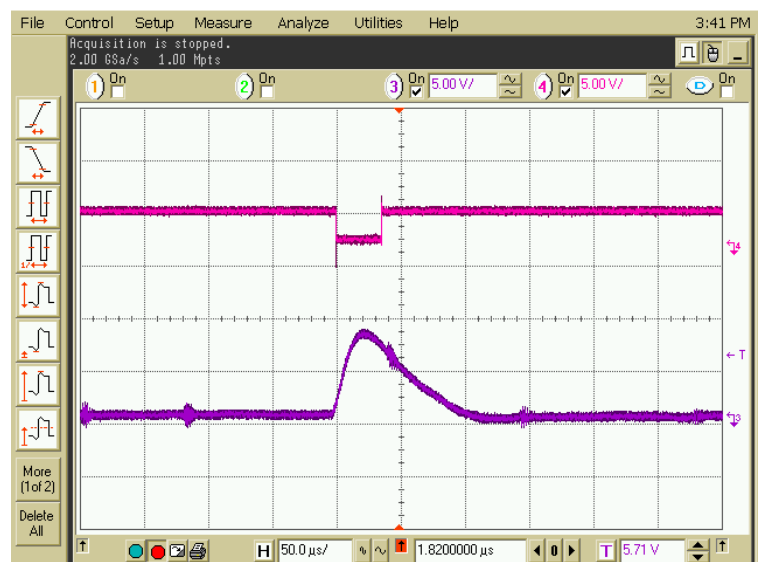

Figure 14. MPFD pulses during KSU TRIGA reactor testing

\subsubsection{KSU Research Facilities}

KSU experience in producing the initial MPFD prototypes was beneficial for producing updated versions of neutron detectors that utilize the MPFD technology. KSU has several specialized laboratories to aid in the construction and testing of various radiation detectors. ${ }^{16}$ through ${ }^{18} \mathrm{KSU}$ specialties in the fabrication and implementation of the MPFD technologies include: building, testing, and optimizing detector ampli- 
fier boards for the MPFD technology; innovative fissile deposition for the MPFD technology; and evaluating the detectors in their nuclear reactor. This section summarizes KSU capabilities utilized for this effort.

\subsubsection{SMART Laboratory}

The Semiconductor Materials and Radiological Technologies (SMART) Laboratory at KSU is a unique facility dedicated to the research and development of new and innovative radiation detector technologies. The SMART Laboratory houses specialized equipment to support that work, including clean rooms, a fission chamber plating station, a linear drive diamond cutting wheel, a diamond wire saw, precision lapping and polishing machines, a 6-pocket e-beam evaporator (Figure 15), an ion mill, a vacuum annealing chamber, microscopes, ovens, grinders, an assortment of furnaces for annealing, sintering, diffusions, and oxidations, a scanning electron microscope, an Auger electron analyzing system, IV and CV tracers, radiation sources, and NIM electronics to test and characterize radiation detectors and materials. In addition, the SMART Laboratory completed construction of a new 1000 square foot class 100 clean room facility that has been fully operational as of March 2012. ${ }^{16}$

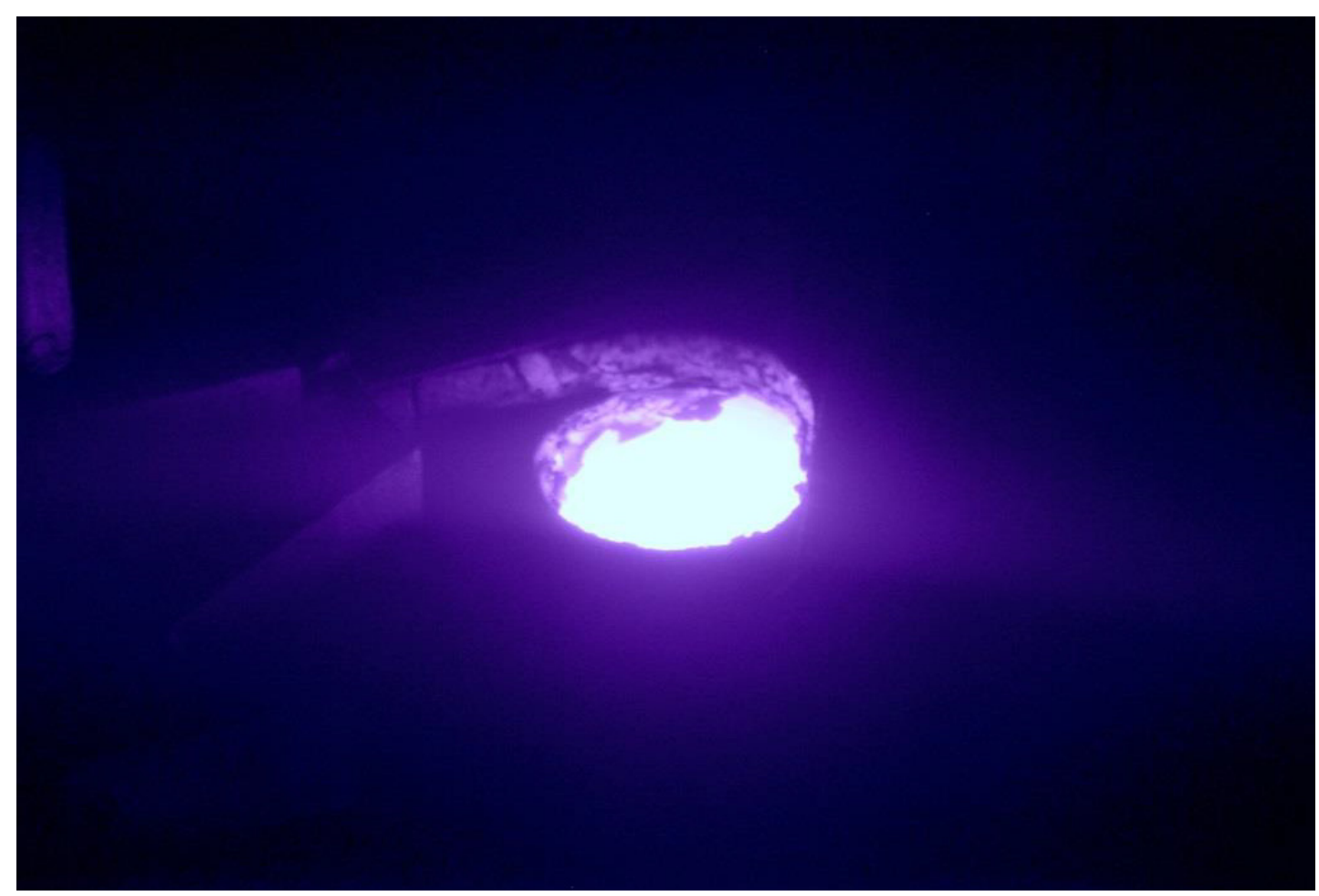

Figure 15. Electron-beam evaporator depositing material at the KSU SMART Laboratory

The facility is available to students and faculty for research and development of sensors. The SMART Laboratory serves as a center for undergraduate and graduate student education as well as a facility to accommodate funded research projects from various government and industrial sponsors. ${ }^{16}$ 


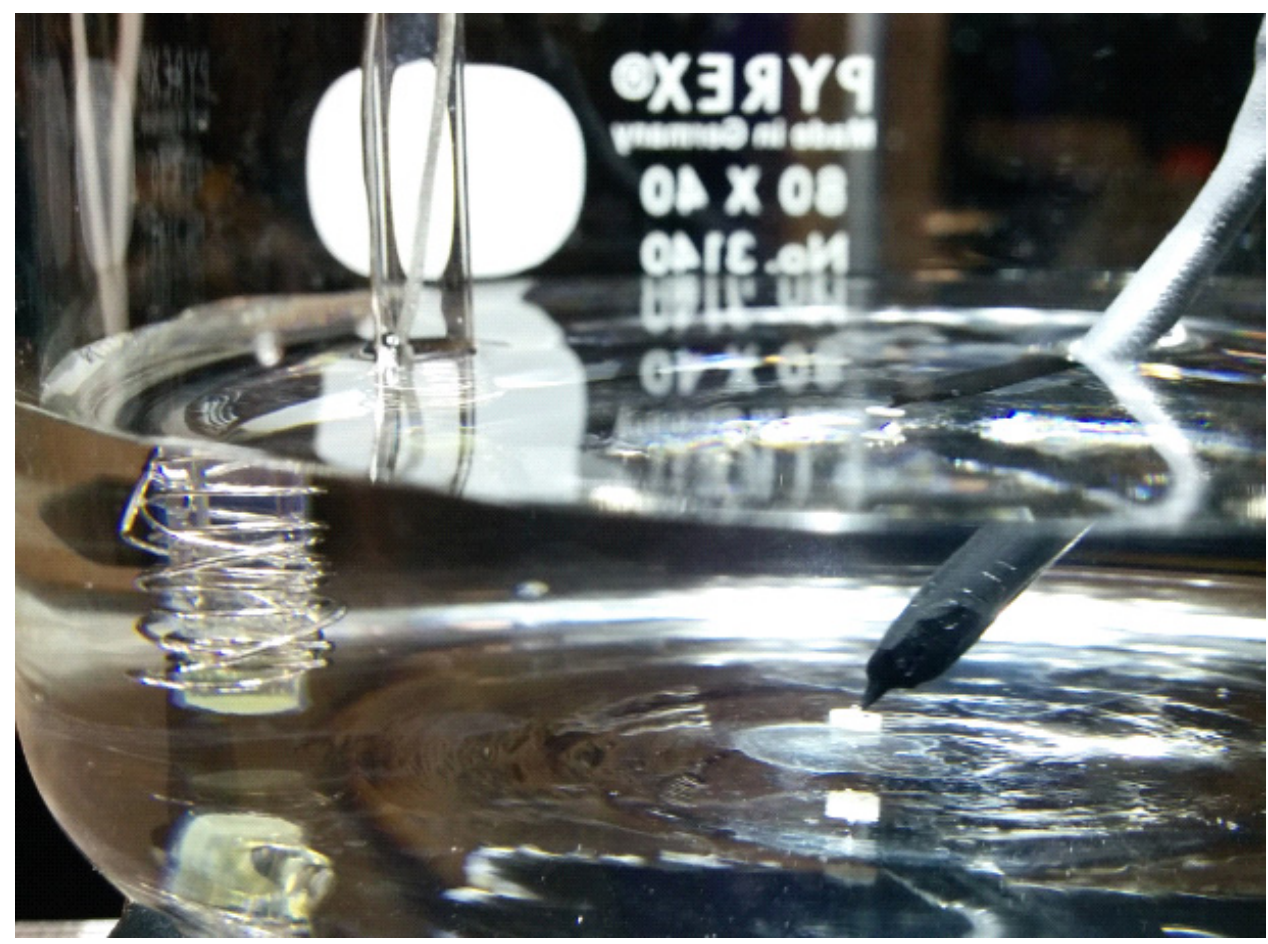

Figure 16. MPFD sample undergoing micro-electroplating of fissile material at the KSU SMART Laboratory

\subsubsection{TRIGA Mark II Research Reactor}

The TRIGA Mark II research reactor at KSU supports education, research, training, and regional industries. The reactor is used extensively by the SMART Laboratory for testing of radiation sensors and irradiation of materials. The KSU TRIGA is licenced to a 1.25 MW steady state operating power and has pulsing capabilities up to $\sim 2 \mathrm{GW}$, making it ideally suited for testing sensors in high-power transients. The peak steady-state thermal flux and fast flux available in-core are approximately $2.50 \times 10^{13} \mathrm{n} / \mathrm{cm}^{2}$-s and $2.50 \times 10^{14} \mathrm{n} / \mathrm{cm}^{2}$-s, respectively. ${ }^{17}$ Sensors can be tested from source range to full power in reactor beam ports or directly in the reactor core. In 2015, the Intra Reflector Irradiation System (IRIS) was installed in the reactor to aid in irradiations. IRIS is a system of in-core dry tubes that allows in-core sensor evaluations to be performed without a concern of water ingress as shown in Figure 17. The ease of access to this reactor facility makes it an asset to the SMART Laboratory for neutron detector testing. ${ }^{17}$

\subsubsection{Electronics Design Laboratory}

The KSU Electronics Design Laboratory (EDL) works closely with the SMART Laboratory to develop the required electronics needed to support sensor research and development. EDL's focus is to provide researchers access to advanced electronics and assist with integrating electronics technology into research programs. EDL is an in-house design service for KSU researchers. The staff has both industry and research experience with analog instrumentation and digital design, as well as software development, system engineering, system construction, and project management. ${ }^{18}$ 

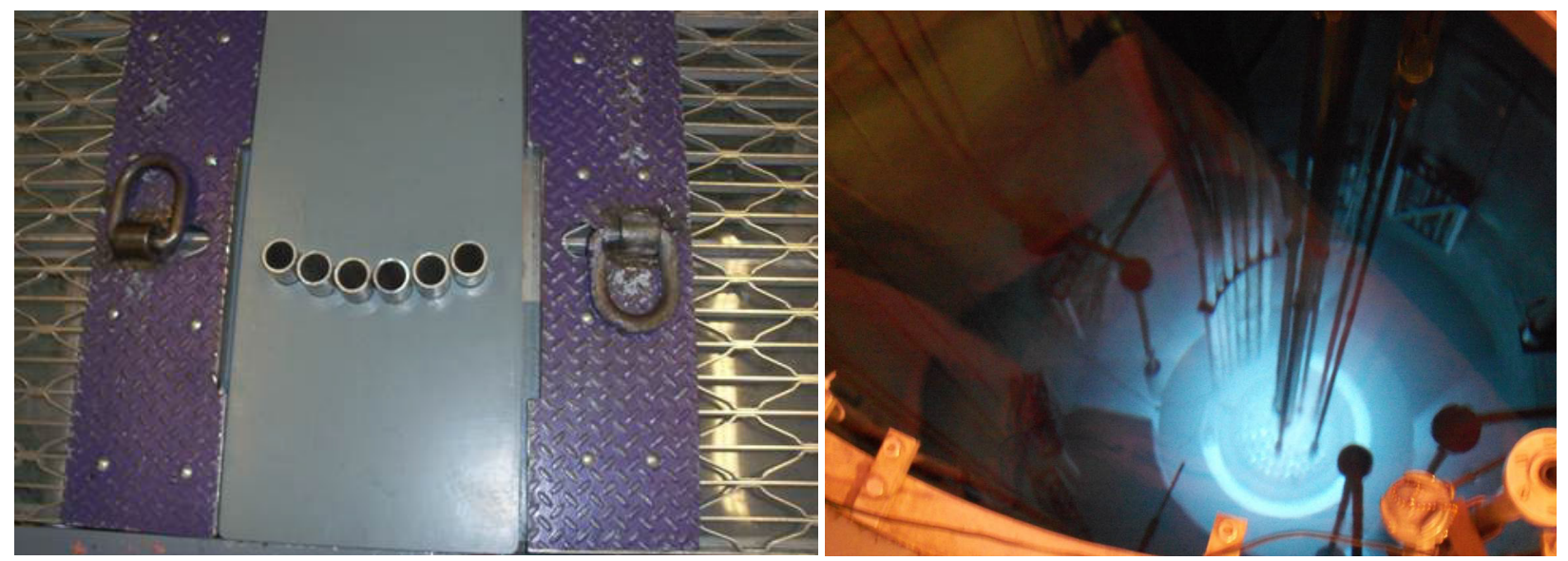

Figure 17. KSU Intra Reflector Irradiation System (IRIS)

\subsubsection{INL Research Facilities}

The INL's role in developing the MPFD technology utilizes its experience in developing and deploying unique in-pile instrumentation suitable for irradiation testing programs that operate in high flux and high temperature conditions. This section summarizes INL capabilities utilized for this effort.

\subsubsection{High Temperature Test Laboratory}

INL has several specialized facilities to construct and test high performance instrumentation. The High Temperature Test Laboratory (HTTL) contains specialized equipment to design advanced in-pile sensors and conduct high-temperature testing. HTTL's trained staff evaluates high-temperature material properties and develops custom high-temperature instrumentation for nuclear and non-nuclear applications, including new methods for measuring temperature, thermal conductivity, localized heating, and sample deformation in MTRs. In addition, the HTTL houses specialized equipment to support such work, including high-temperature tube furnaces, a high-temperature vacuum furnace, swagers, a draw bench, a laser welder, a helium leak detector system, a real time X-ray imaging system, several autoclaves, and various high-temperature material property measurement systems to provide comparison data (see Figure 18). HTTL efforts support DOE-NE programs that require specialized in-pile sensors for fuels and materials irradiations. ${ }^{19}$

In 2014, the HTTL was relocated to a new state-of-the-art facility at INL, the Energy Innovation Laboratory (EIL) (see Figure 18). The inclusion of a clean room capability and additional new state-of-the-art equipment including a three-dimensional computed tomography system, fiber laser welder, and electron beam welder furthers HTTL's role as a world-class in-pile instrumentation development and testing facility. $^{20}$

INL capabilities also include two unique facilities for testing in neutron and gamma fields, the ATR Critical facility (ATRC) and the Health Physics Instrument Laboratory (HPIL). A brief description of each of these facilities is provided below. In addition, calibration activities performed at the ATRC are presented. 


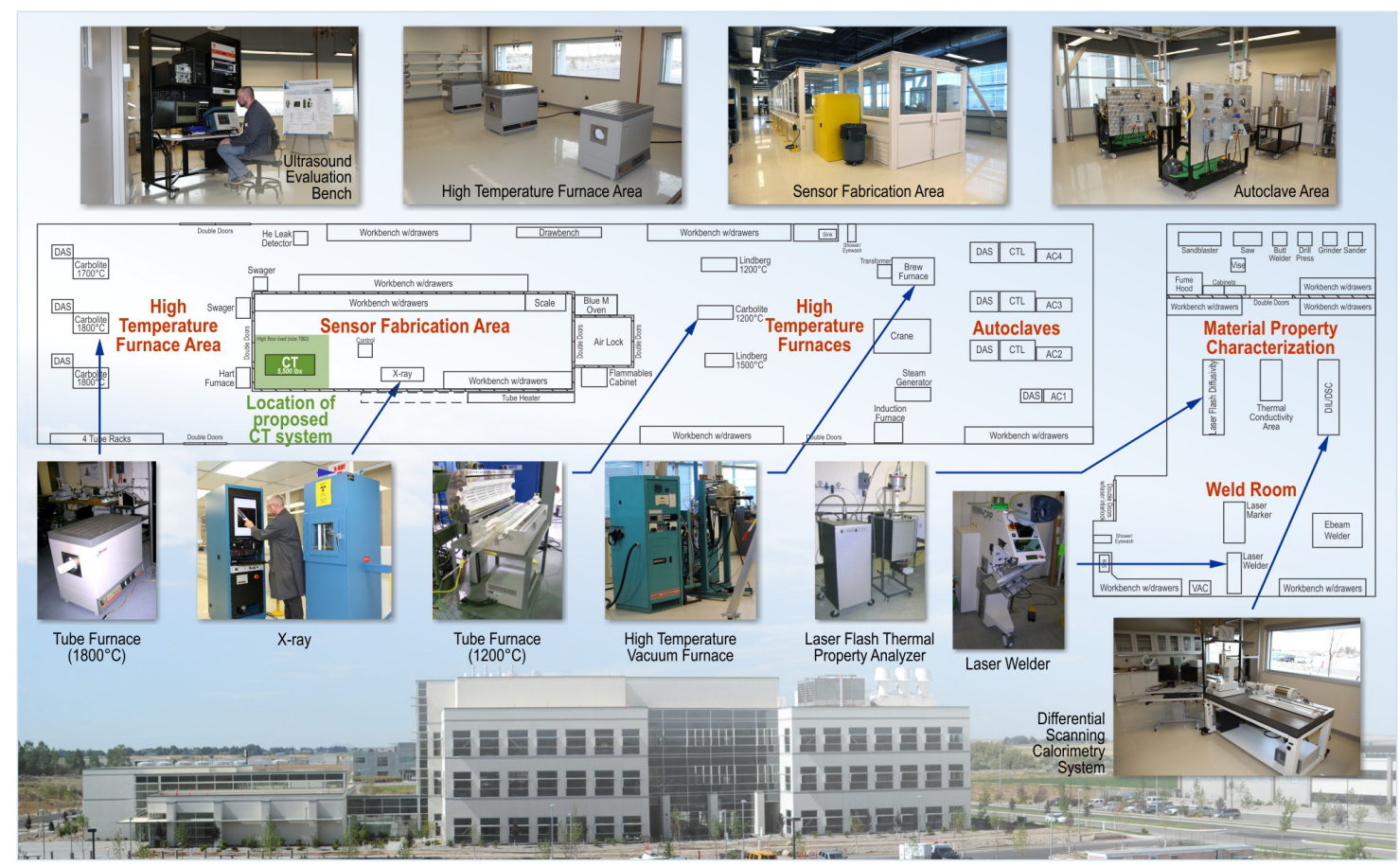

Figure 18. HTTL layout in the new Energy Innovation Laboratory

\subsubsection{ATRC Facility}

The ATRC core is a nearly-identical full-scale nuclear mock-up of the ATR core and can provide valuable insight into the use of advanced sensors prior to deployment in the ATR. The current mission of the ATRC is to obtain accurate and timely data on nuclear characteristics of the ATR core, such as rod worths and calibrations, excess reactivities, neutron flux distribution, gamma-heat generation rates, fuel loading requirements, and effects of the insertion and removal of experiments. The ATRC provides a necessary supplement to analytical reactor methods that support ATR operation. Although the ATRC typically operates at power levels of 600 watts or less, its authorized maximum power level is $5 \mathrm{~kW}$. The core power is maintained at low levels to minimize radiation exposures during manual operations required to unload experiments and fuel. As discussed within this section, an ATR NSUF project has developed and installed Experiment Guide Tubes (EGTs) into ATRC irradiation positions (Figure 19). This recently developed specialized fixturing provides INL a unique capability for comparison evaluations of real-time neutron flux detectors. $^{21}$

\subsubsection{HPIL Facility}

The HPIL is the primary radiation protection instrumentation calibration facility at the INL. The HPIL includes two irradiators for detector evaluations. The first irradiator at the Low Scatter Facility houses a National Institute of Standards and Technology (NIST) traceable Cf-252 neutron source that provides a 10 $\mathrm{rem} / \mathrm{hr}$ neutron dose rate. The second irradiator, the Gamma Beam Irradiator houses NIST traceable Cs-137 and Co-60 gamma sources of $800 \mathrm{R} / \mathrm{hr}$ and $400 \mathrm{R} / \mathrm{hr}$ dose rates, respectively. ${ }^{22}$ 
These irradiators and the ATRC were not able to be incorporated into prior evaluations for the previous NEET ASI MPFD project due to time constraints associated with evaluations scheduled at the KSU TRIGA reactor. It is planned that the NEET ASI HT MPFD project will use the irradiators and the ATRC to test the neutron sensitivity and the gamma-ray insensitivity of the HT MPFDs.

\subsubsection{Flux Detector Calibrations at ATRC}

As noted in Section 3.2.4.2, ATRC research funded by an ATR NSUF program has resulted in neutron detector evaluation capabilities at INL that are beneficial to HT MPFD development. The project, a joint ISU/CEA/INL collaboration, was initiated to investigate the feasibility of using neutron sensors to provide online measurements of the neutron flux and fission reaction rate in the ATRC. The project cross-calibrated various activation detectors (foils and wires), miniature fission chambers, SPNDs and back-to-back (BTB) fission chambers in the ATRC. The SPNDs under evaluation had hafnium, gadolinium and rhodium emitters for thermal neutron detection. The fission chambers under evaluation had U-235 fissile deposits for thermal neutron detection and U-238 fissile deposits for fast neutron detection. The in-core sensors were inserted into the ATRC using EGTs (Figure 19) and also installed in the northwest in-pile tubes.

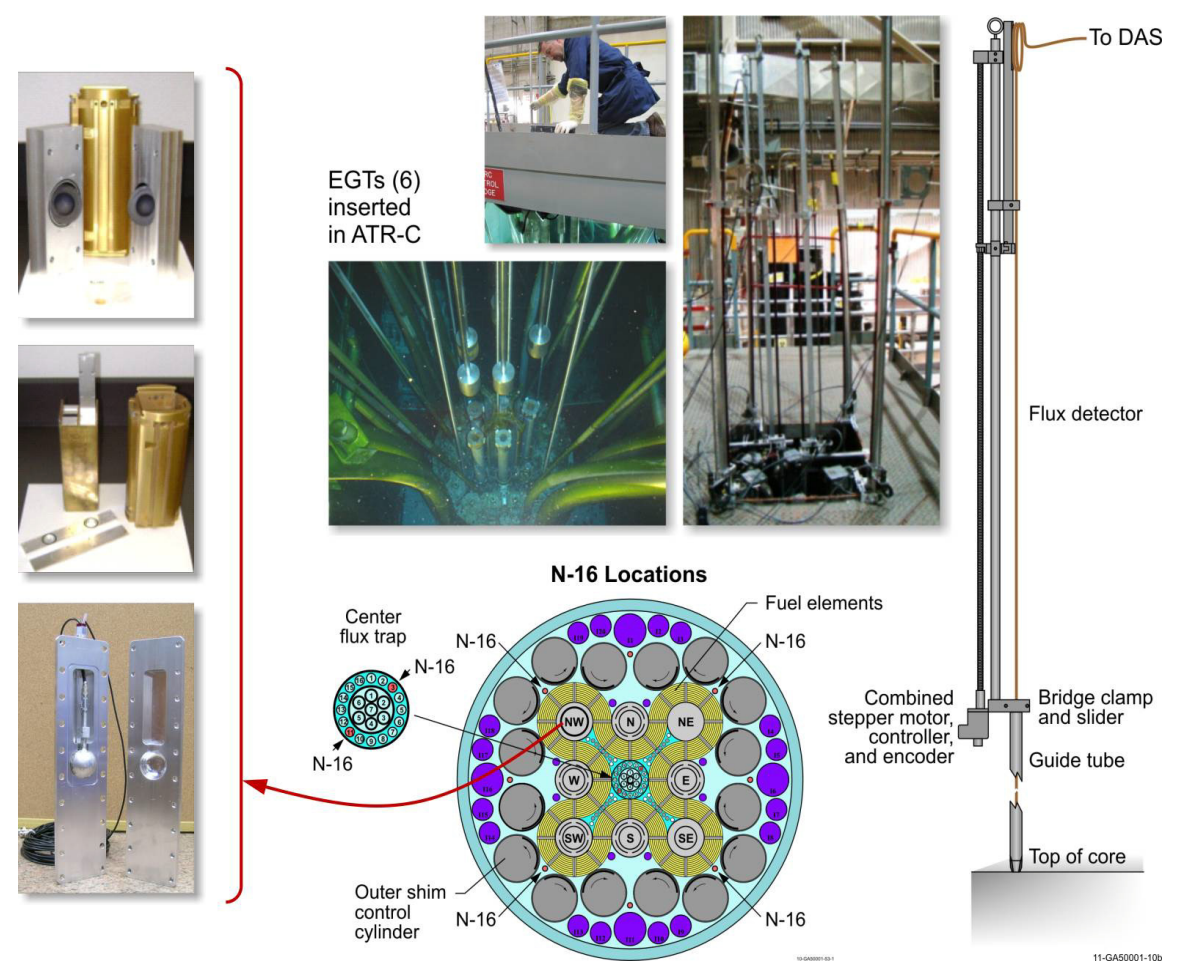

Figure 19. In-core sensors installed in the ATRC

Detector evaluations were performed for a variety of operational conditions in 2013. The reactor was brought to specified power levels between $0.01 \mathrm{~W}$ and $600 \mathrm{~W}$. In addition, measurements were taken with the reactor shut down prior to startup and with the reactor shut down after startup. In order to assess if the detectors could be used to monitor various power splits, the reactor was purposely operated in an unbalanced condition, meaning the reactor power in the NW lobe was purposely changed from the nominal critical power level. 
Initially, the flux sensors were verified to be operational; then, the detectors were used to track reactor power. Typical data obtained from axial flux testing and power level testing is shown in Figure 20. In addition to data collection, various insights were gained during the testing of the in-core sensors related to installation, operation, and data analysis. Additional details related to this testing are documented in References 23,24 and 25 .
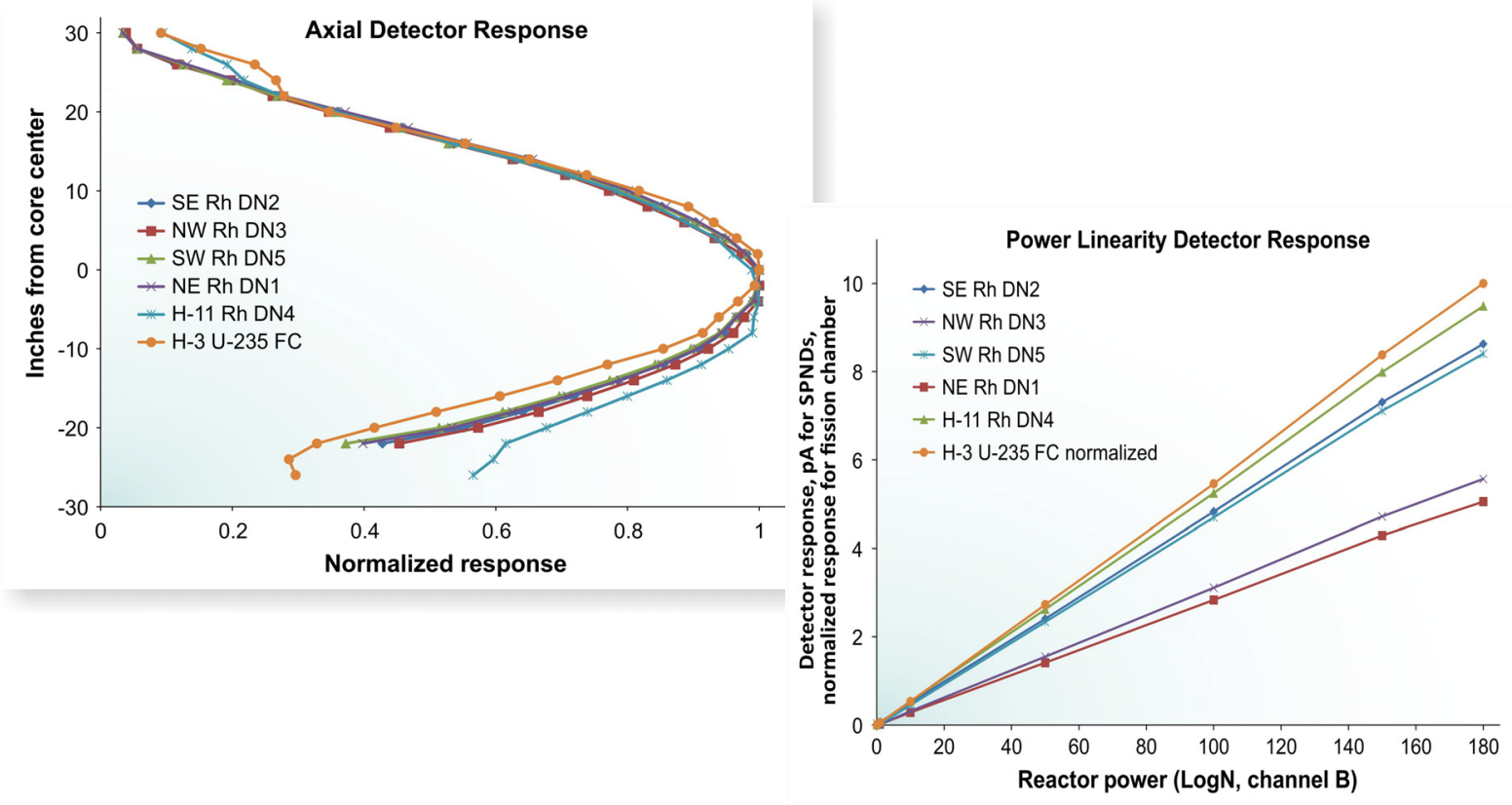

Figure 20. Axial flux profile and power measurements obtained from rhodium SPNDs and a fission chamber

Other cross-calibration fixtures for ATRC were tested in 2014. Specialized fixtures allowed a BTB fission chamber to be inserted into the ATRC. The BTB fission chambers, which are often called $2 \pi$ fission chambers because they are designed to count almost all fission fragments emitting from a thin deposit in a $2 \pi$ solid angle, provide the most accurate measure of fission reaction rates and provide accurate cross-calibrations of other detectors such as a HT MPFD. These fixtures place a BTB fission chamber in the ATRC core alongside other in-core sensors to compare their response in near-identical flux conditions. Further experimental details can be found in Reference 25 .

\subsubsection{CEA Contributions}

The CEA has over 40 years of experience in design, construction and use of miniature and sub-miniature fission chambers for MTR experiments. The CEA has developed many specialised computed modeling codes to aid in fission chamber research and development. The CEA contribution to this project was to provide technical guidance and modeling capabilities as needed. 


\subsection{Current HT MPFD Developments}

Previous research conducted through NEET ASI ${ }^{1-3}$ has shown that the MPFD technology could be made robust and was successfully tested in a reactor core. This new project will further develop the MPFD technology for higher temperature regimes and other reactor applications. This HT MPFD will be developed, fabricated, and evaluated using techniques perfected by INL's HTTL staff during development of other high temperature in-pile sensors, equipment and knowledged possessed by KSU for material depositions and electronics design, and the expertise in miniature fission chamber design possessed by CEA.

\subsubsection{Project Kickoff Meeting}

As part of the FY15 activities, a project kickoff meeting was held at KSU on December 19, 2014, to discuss the HT MPFD design and project schedule, objectives, deliverable and milestones. The meeting focused on understanding the challenges associated with a new HT MPFD design for higher temperatures. Several options for alternate construction methods and equipment were discussed by KSU and INL. In addition, a demonstration of the current efforts in electroplating of fissile materials for the HT MPFD was given.

\subsubsection{High Temperature Sensor Design for MTR Irradiations}

DOE-NE programs require a robust and reliable sensor that will survive the harsh testing conditions possible in US MTRs. Hence, an high temperature fission chamber that utilizes the MPFD technology is undergoing development in this NEET project, as a collaboration between INL, KSU and CEA. The HT MPFD utilizes design characteristics successfully deployed in other INL-developed high temperature in-pile sensors. In addition to the newly identified high temperature compatible materials, the HT MPFD design uses a similar round stackable geometry as previous robust MPFD designs (Figure 9), but the locates a thermocouple in the extension cable of the detector (Figure 21).

\subsubsection{Electronics for HT MPFD}

The KSU EDL is responsible for the circuit design of the signal amplifiers required for HT MPFD operation. The new design of the HT MPFD, required adjustments to the standard MPFD signal amplifier. Circuit design remained relatively unchanged, but component values were updated as necessary. The amplifier board is powered by $\pm 12 \mathrm{~V}$ and $+5 \mathrm{~V}$ and incorporates $5 \mathrm{~V}$ logic signals outputting two channels of analog pulse, analog current and digital timing. Several amplifiers have been assembled at the KSU EDL (Figure 22) and tested successfully with an MPFD at the TRIGA reactor.

\subsubsection{HT MPFD Plating System}

The KSU SMARTLab is responsible for plating all coatings required for HT MPFD construction. Two plating steps are performed; the first step is to plate the electrical contacts or electrodes on the alumina substrates. The second plating step is to deposit the fissile material on one of the electrical contacts. 


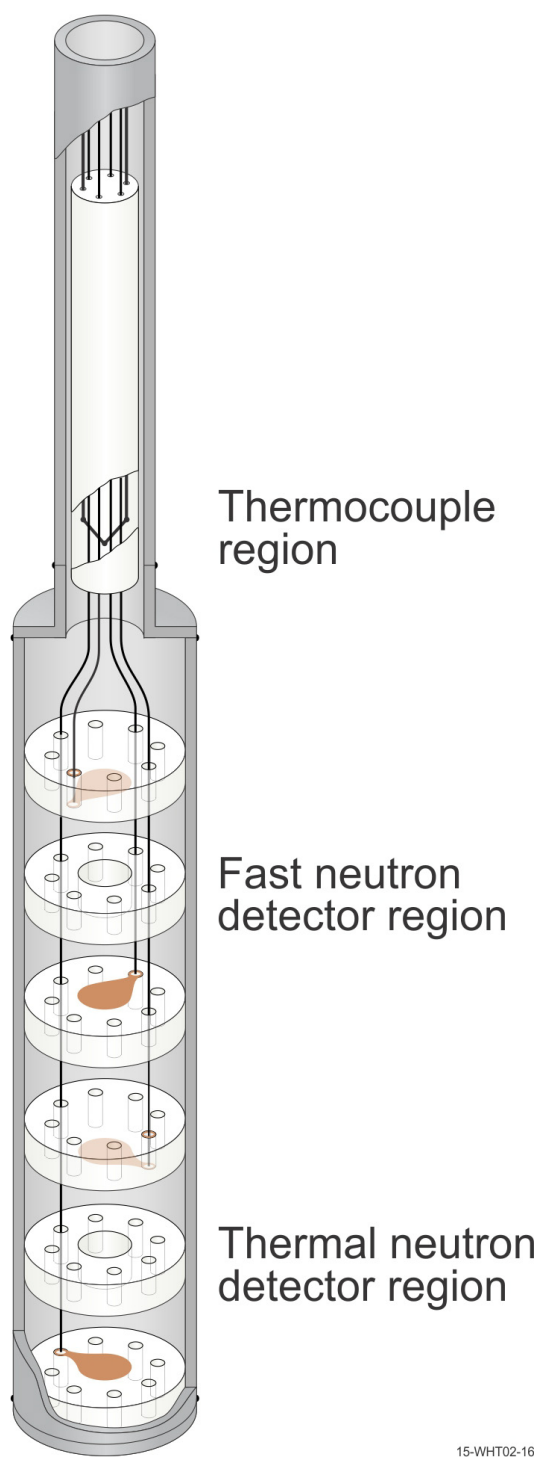

Figure 21. HTMPFD assembly shown in tube with thermocouple in extension cable

The initial plating to deposit the electrical contacts is performed using an electron-beam evaporator (Figure 15). The plating requires custom shadow masks for the HT MPFDs to be machined using a micro-milling machine at KSU. The purpose of the shadow masks is to selectively deposit the contact material that defines the electrical contacts and wire-bonding pad. Titanium and platinum are used as the contact materials. A thin layer of titanium is used to attached to the alumina, then a thicker layer platinum is used for the electrical contact and to provide a basis for the fissile material electroplating.

Once the electrical contacts are in place, the second plating step will deposit the material. Natural uranium is used for thermal neutron detection and thorium is used for fast neutron detection, but other fissile materials could be deposited to alter signal response as requested by irradiation programs. Standard micro-electroplating methods are used to deposit the fissile materials. The small substrates and thin depositions utilize a specialized nA-current micro-electroplating system at KSU (Figure 24). 


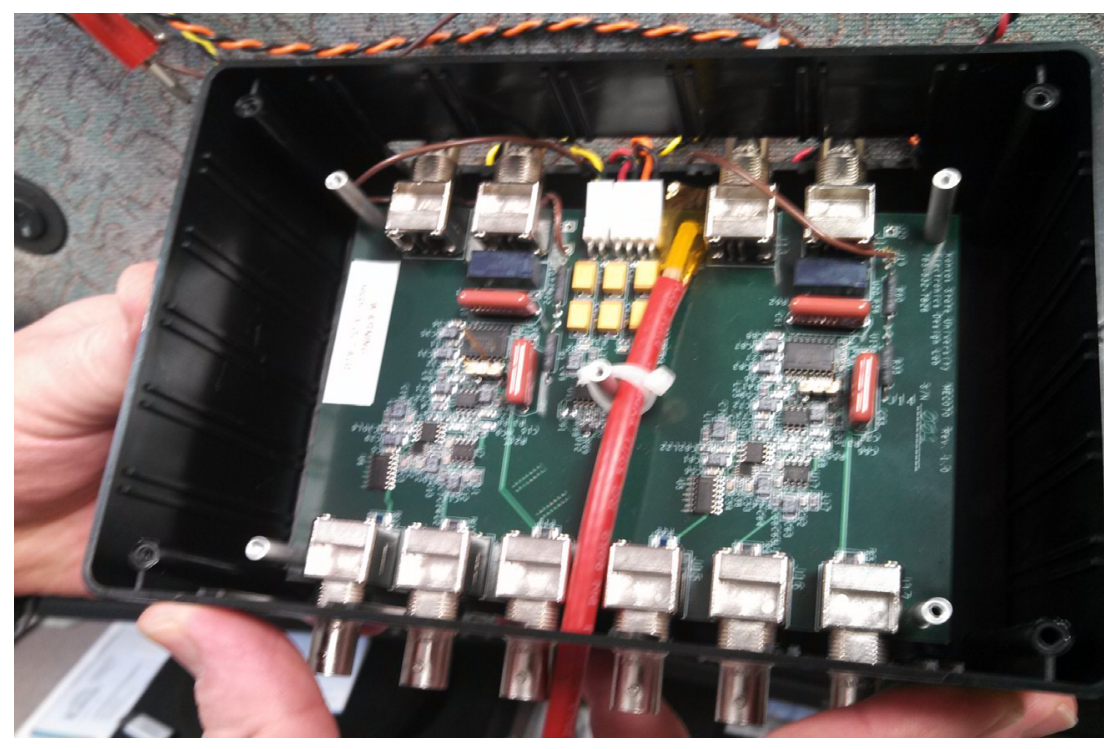

Figure 22. MPFD amplifier used for testing at KSU TRIGA reactor

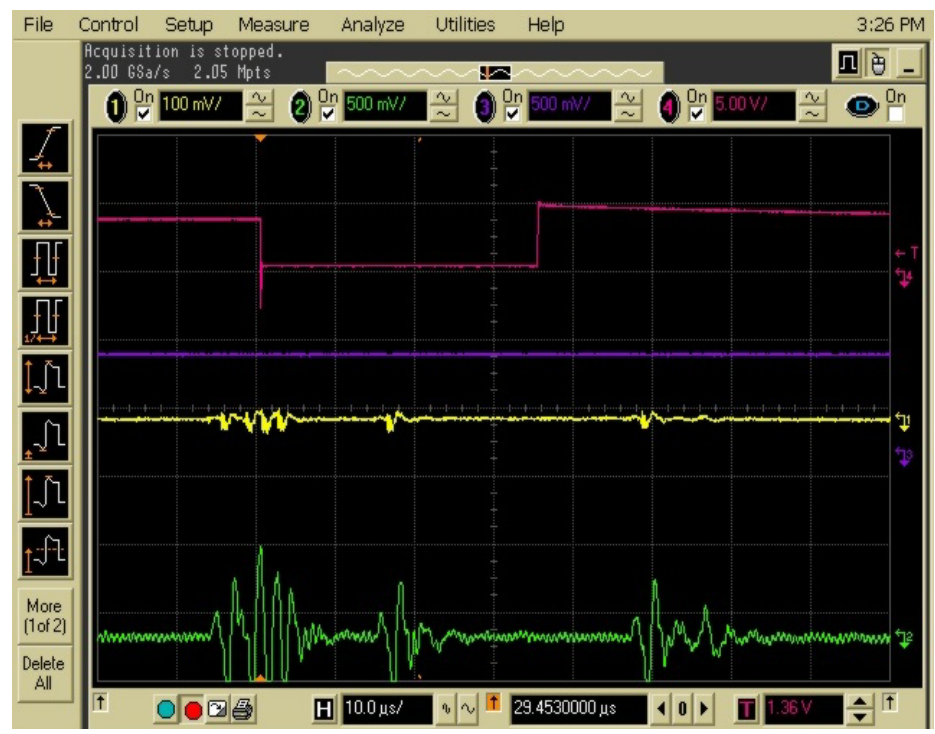

Figure 23. Analog and digital signals from MPFDs in KSU TRIGA reactor

Contact deposition quality has been verified by using an optical profilometer (Figure 25) x-ray fluorescence analyzer, and electrochemical analyzer. In addition, the fissile deposit characterization is completed by using a specialized $2 \pi$ solid angle gas detector to verify the amount of material deposited is consistent with predictions.

\subsubsection{Design and Materials}

The HTTL's expertise in robust sensors for MTR irradiations was used to improve the design for the HT MPFD. Using this expertise, the round, stackable geometry that is more suitable for installation in a 


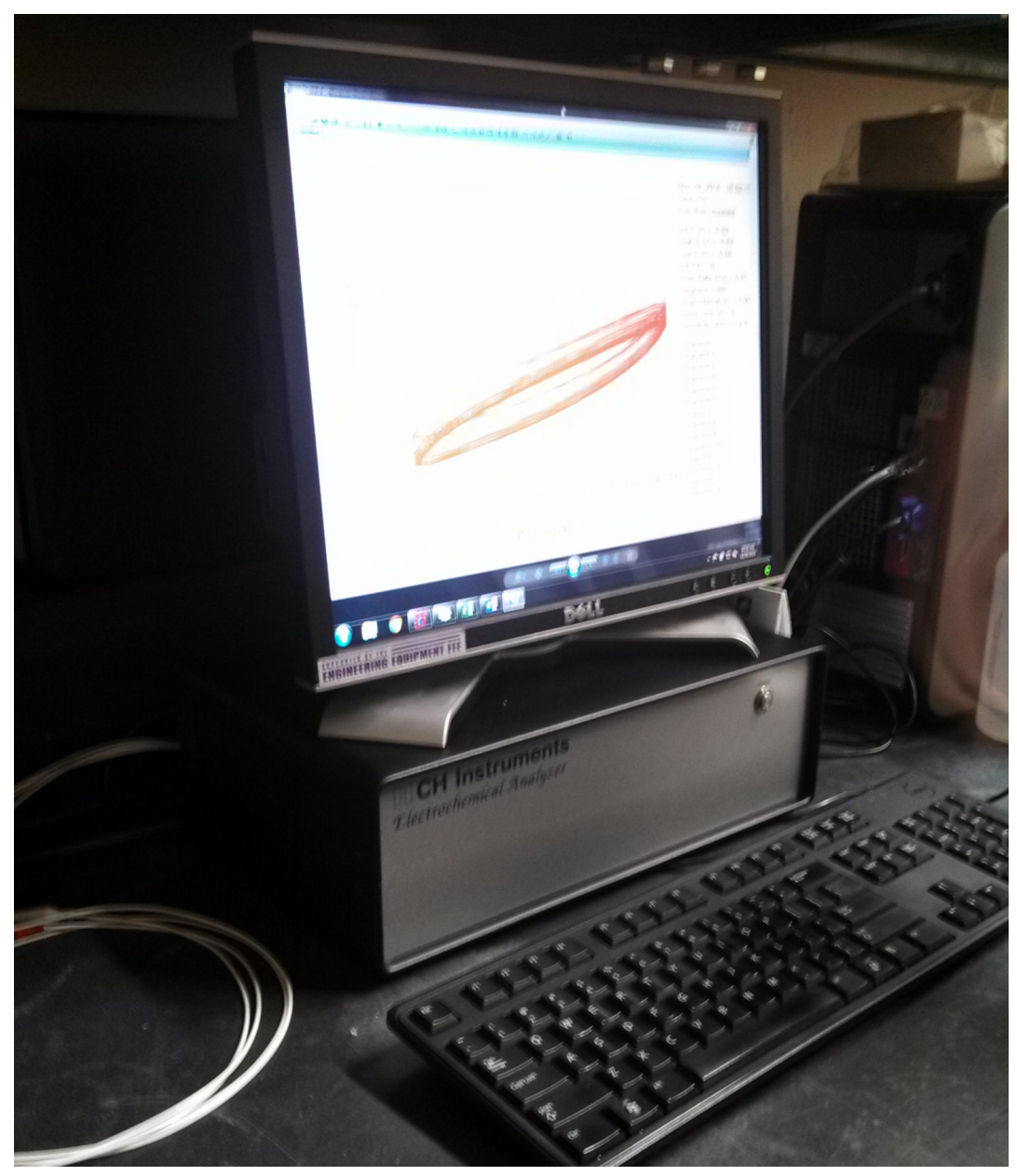

Figure 24. Micro-electroplating system at KSU

leak-tight tube and that has improved thermocouple connections and wiring transitions was maintained. Careful material selection should allow the HT MFPD to be capable of operating at temperatures up to 800 ${ }^{\circ} \mathrm{C}$.

The main components of the HTMPFD detector and extension cable are specially manufactured hard-fired ultra smooth alumina substrates and crushable alumina insulators (Figure 26), respectively, all housed within leak-tight tubing. The outer sheath was changed from the stainless steel (Figure 27) that was used in previous MPFD designs to Inconel for improved survivability in high temperatures and in harsh irradiation conditions. Wiring and tube-to-tube transitions use specially machined Inconel adapters that position the tubes uniformly for welding repeatedly. In addition, a tube cap was specially machined for the loose assembly tube for a tight fit. A "loose assembly construction" will be used with a rigid Inconel tube for the active area of the sensor. Modeling has shown that a wall thickness of 0.020 " will allow the integrity of the sheath to survive in accident conditions up to 8000psi. This tube contains hard-fired alumina substrates for the fission chamber electrodes and the fissile depositions and wire contacts. The crushable alumina insulators serve as an insulator for the six wire extension cable that also utilizes an Inconel outer sheath . In addition, the HT MPFD design moves the thermocouple to the extension cable to improve thermocouple response. 

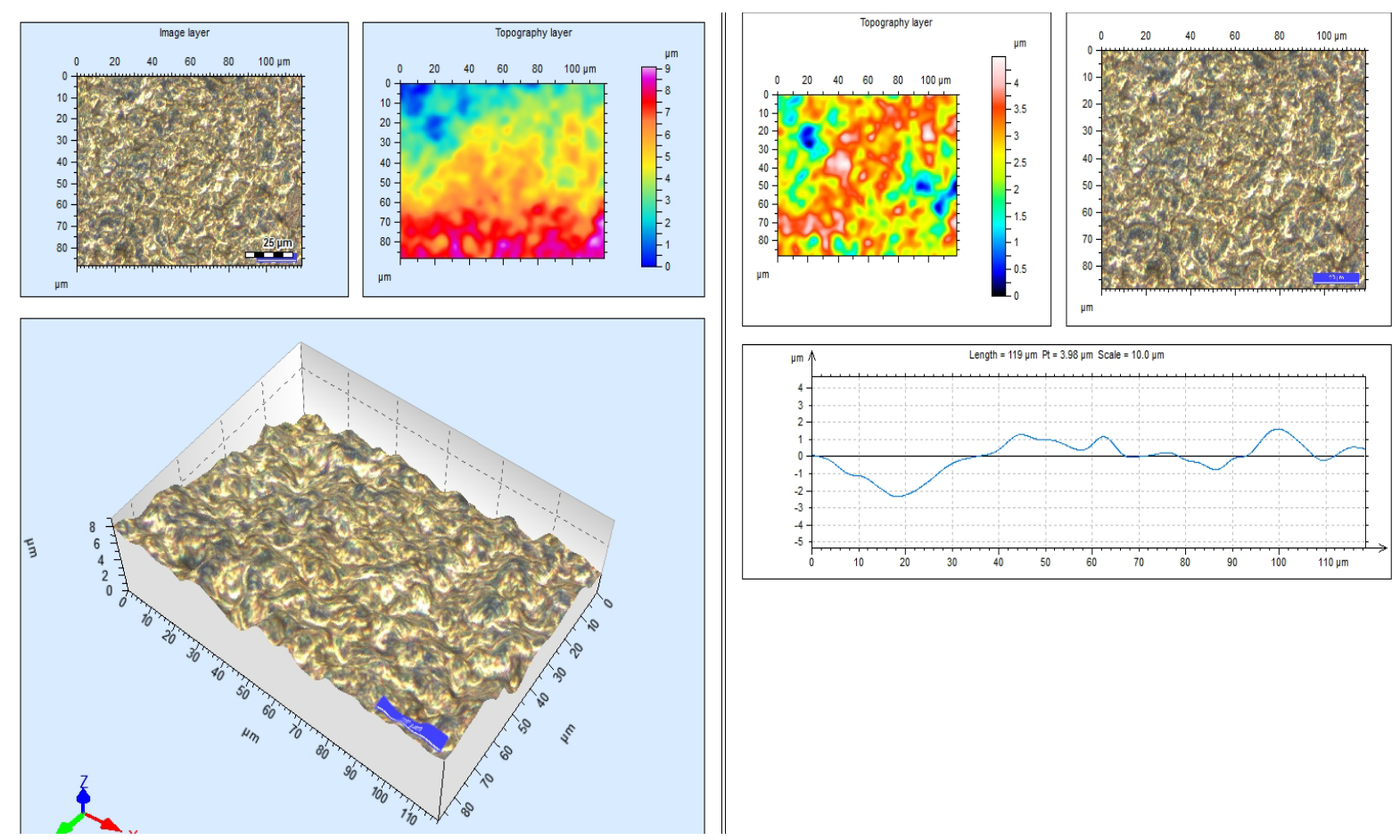

Figure 25. Electroplated sample of uranium under analysis with optical profilometer

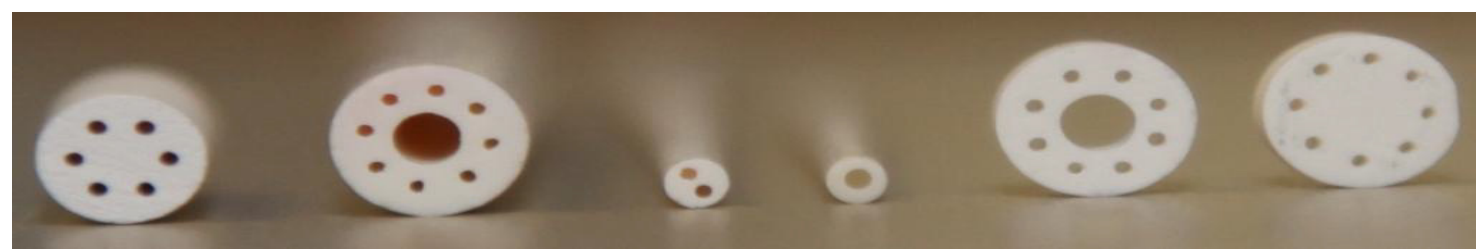

Figure 26. MPFD alumina substrates and insulators

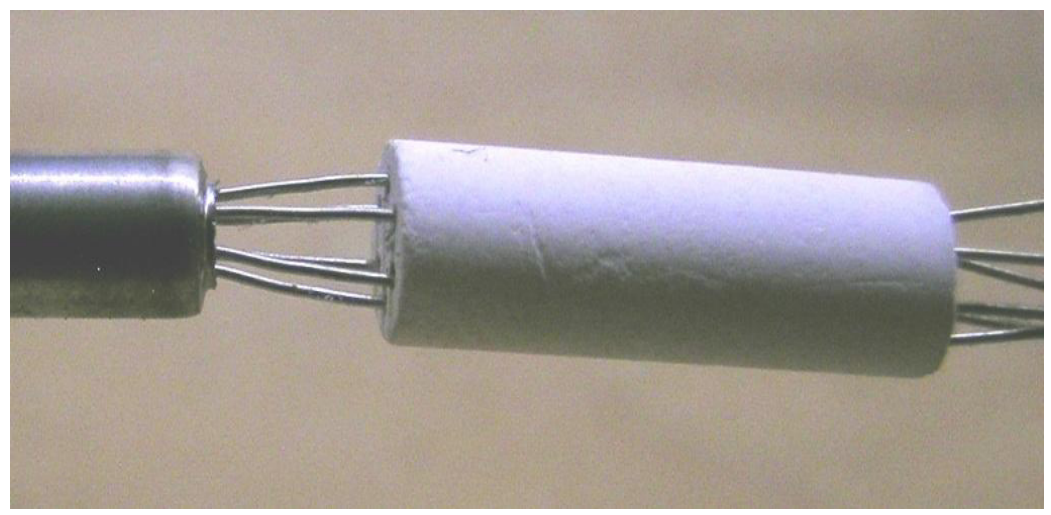

Figure 27. Extension cable with six wires threaded through insulation 


\subsubsection{Construction Methods}

HT MPFD construction will use similar equipment and techniques perfected by INL's HTTL staff as for other in-pile sensors. The unique design of the MPFD requires several construction steps that aren't required for conventional in-pile sensor fabrication. Specifically, specialized techniques have been developed that emphasize robustness that include minimizing the number of wire splices and difficult to manufacture wiring transitions. Figure 28 shows some of the specialized HTTL equipment used in previously fabricated MPFDs that is expected to be used in the HT MPFD fabrication. The final assembly of the HT MPFD will look similar to previous designs of the robust MPFDs (Figure 29), but utilizes improved materials and construction techniques to survive at temperatures up to $800^{\circ} \mathrm{C}$.

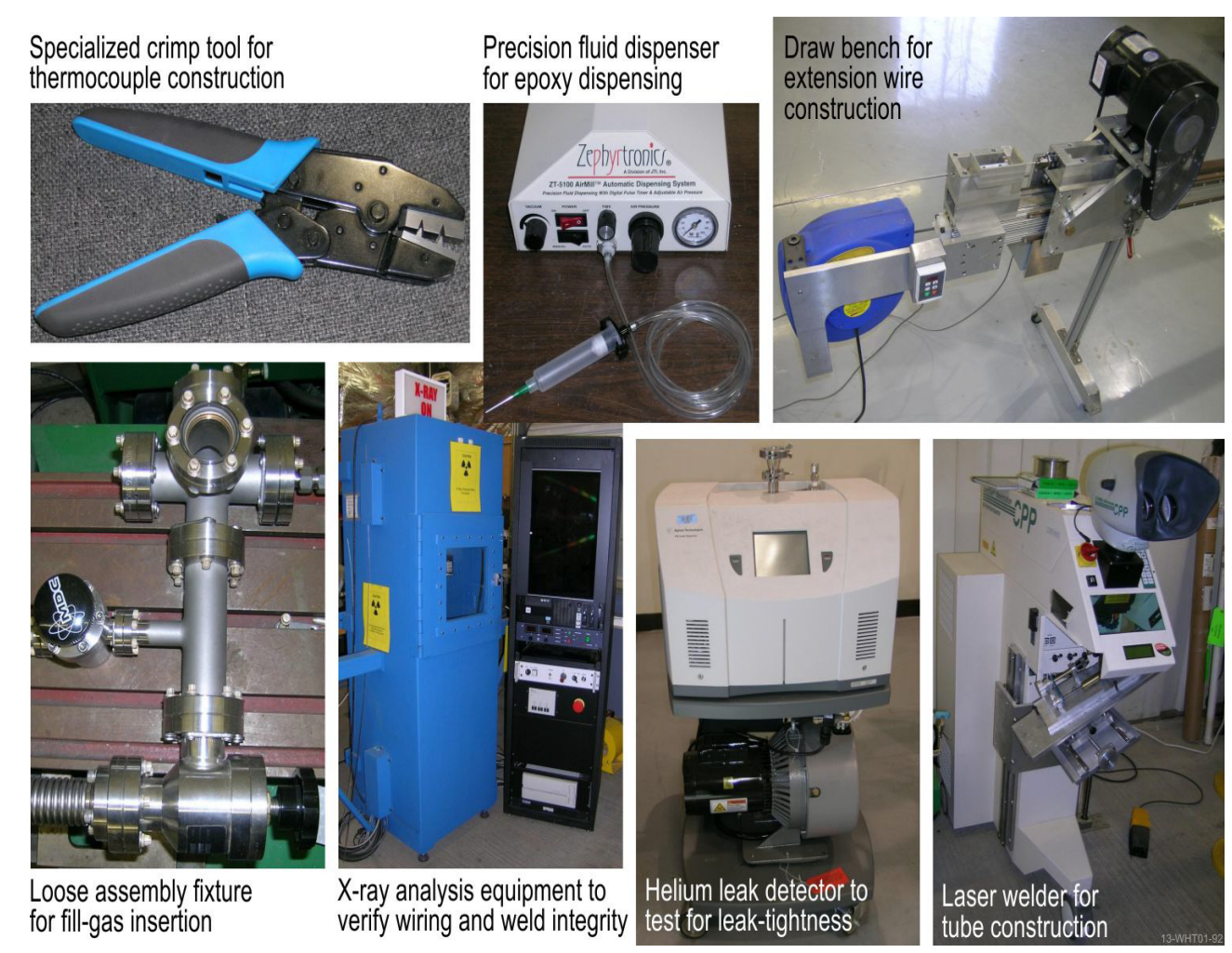

Figure 28. Various HTTL equipment for MPFD fabrication

\subsubsection{HT MPFD Design Improvement Summary}

The HTMPFD redesign was achieved by making minor adjustments to proven design and construction methods. More robust materials were chosen where appropriate including the robust Inconel sheath and ultra smooth alumina parts. In addition, the design was changed to move the thermocouple to the extension cable so that it would respond faster to temperature changes then previous MPFD designs that located the thermocouple in the more insulated loose assembly area. The electroplating and fissile deposition process are under continual testing and improvement to fully characterize the processes. In addition, ongoing research on MPFD development and evaluations has been accepted for publication in Annals of Nuclear Energy. ${ }^{26}$ 


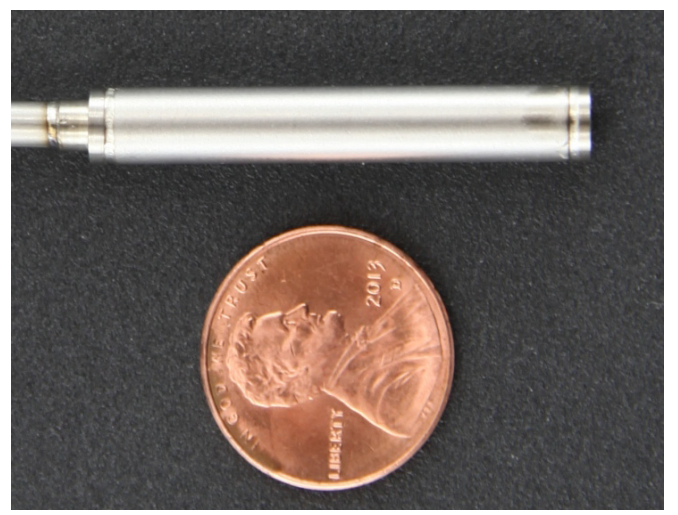

Figure 29. MPFD assembly size comparison

\subsubsection{MPFD MTR Irradiation Opportunities}

As previously stated, sensors developed for NEET ASI projects should strive to meet irradiation testing program needs. Two MTR irradiation programs have recognized the value of the NEET-developed MPFD technology and are independently funding irradiations of the MPFD technology. These are significant opportunities for the FY15-FY17 NEET Enhanced Micro-Pocket Fission Detector for High Temperature Reactors project because the irradiation expense of these experiments could not be included in the original project scope.

\subsubsection{AGR $5 / 6 / 7$ Irradiation}

The NGNP program is pursing evaluations of a suite of advanced real-time in-core sensors during their 3 year test campaign in the ATR. The AGR 5/6/7 irradiation program is funding the sensor procurement, data acquisition system and engineering effort required to integrate sensors into the test train (Figure 30). The suite of instrumentations includes:

- 1 Ultrasonic Thermometer (NEET-developed sensor)

- 1 Micro-Pocket Fission Detector (NEET-developed sensor)

- 3 Self Powered Neutron Detectors

- 2 High Temperature Ceramic Thermistors

- 1 Fiber Optic Temperature Sensor

- 1 Ionization chamber

The program will use the HT MPFD design (Figure 21), but has requested a change from a Type K to a Type $\mathrm{N}$ thermocouple to match the other thermocouples installed in the test. Both the NEET-developed sensors and the other sensors in these evaluations will be tested at unprecedented flux levels by leveraging the AGR 5/6/7 irradiation program. This evaluation will further demonstrate the usefulness of the MPFD to simultaneously measure fast flux, thermal flux and temperature in a typical ATR long duration irradiation test. 


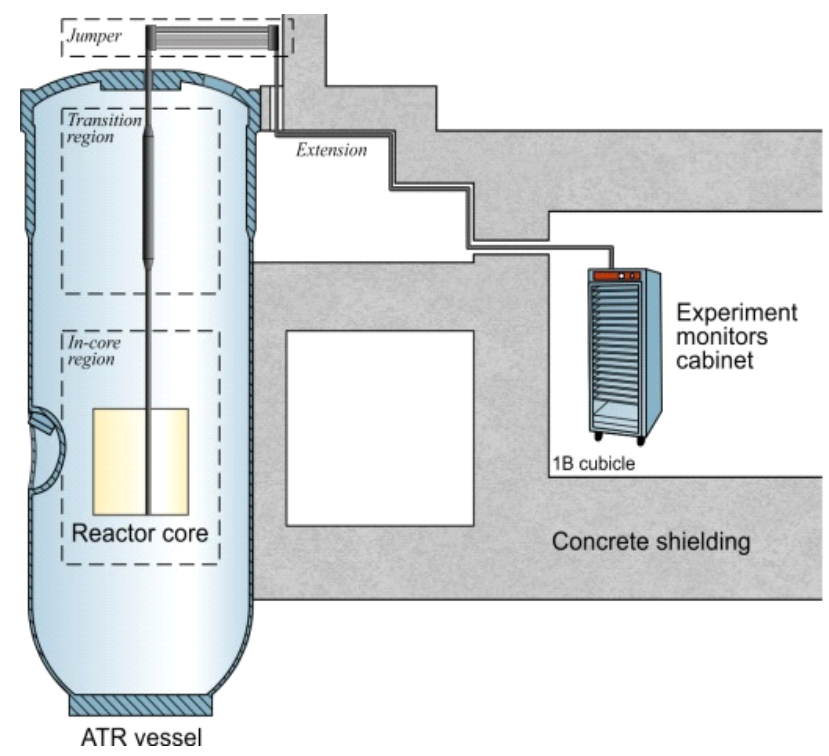

Figure 30. In-core sensor and equipment locations in the AGR 5/6/7 test

\subsubsection{Accident Tolerant Fuels}

The Accident Tolerant Fuels (ATF) program is pursuing the MPFD technology for two irradiations. The first irradiation, ATF-2, will evaluate the a suite of advanced sensors, including the NEET-developed HT MPFD, in the ATR during a sensor qualification test. The ATF-2 irradiation program is funding the construction, installation and testing of a MPFD (along with other advanced sensors) during these irradiations. The irradiation isn't expected to be as long as the AGR 5/6/7 irradiation, but will still provide valuable insight into the operation of a MPFD in a typical ATR irradiation.

The second irradiation, ATF-3, will evaluate a specialized version of the MPFD technology that is suitable for TREAT transients. This version of the MPFD is scheduled to be installed in the multi Static Environment Rodlet Transient Test Apparatus (SRERTTA) as shown in Figure 31 and Figure 32 to aid in the monitoring of experiment transients. ${ }^{27}$ This effort will be a departure from previous MPFD designs because the focus will be on developing a robust, fast response MPFD that has two low efficiency and two high efficiency neutron detectors and does not include a thermocouple as shown in Figure 33. Although the transient-specific MPFD design developed by ATF-3 will be different from other MPFD designs, it is expected that the information gained in the development of this transient-specific MPFD will provide insight into the developmental activates of the NEET Enhanced Micro-Pocket Fission Detector for High Temperature Reactors project. In addition, the information gained from initial ATF-3 irradiations will guide the future use of transient-specific MPFDs for TREAT irradiation testing for various DOE-NE programs requesting advanced instrumentation capabilities for transient testing. 

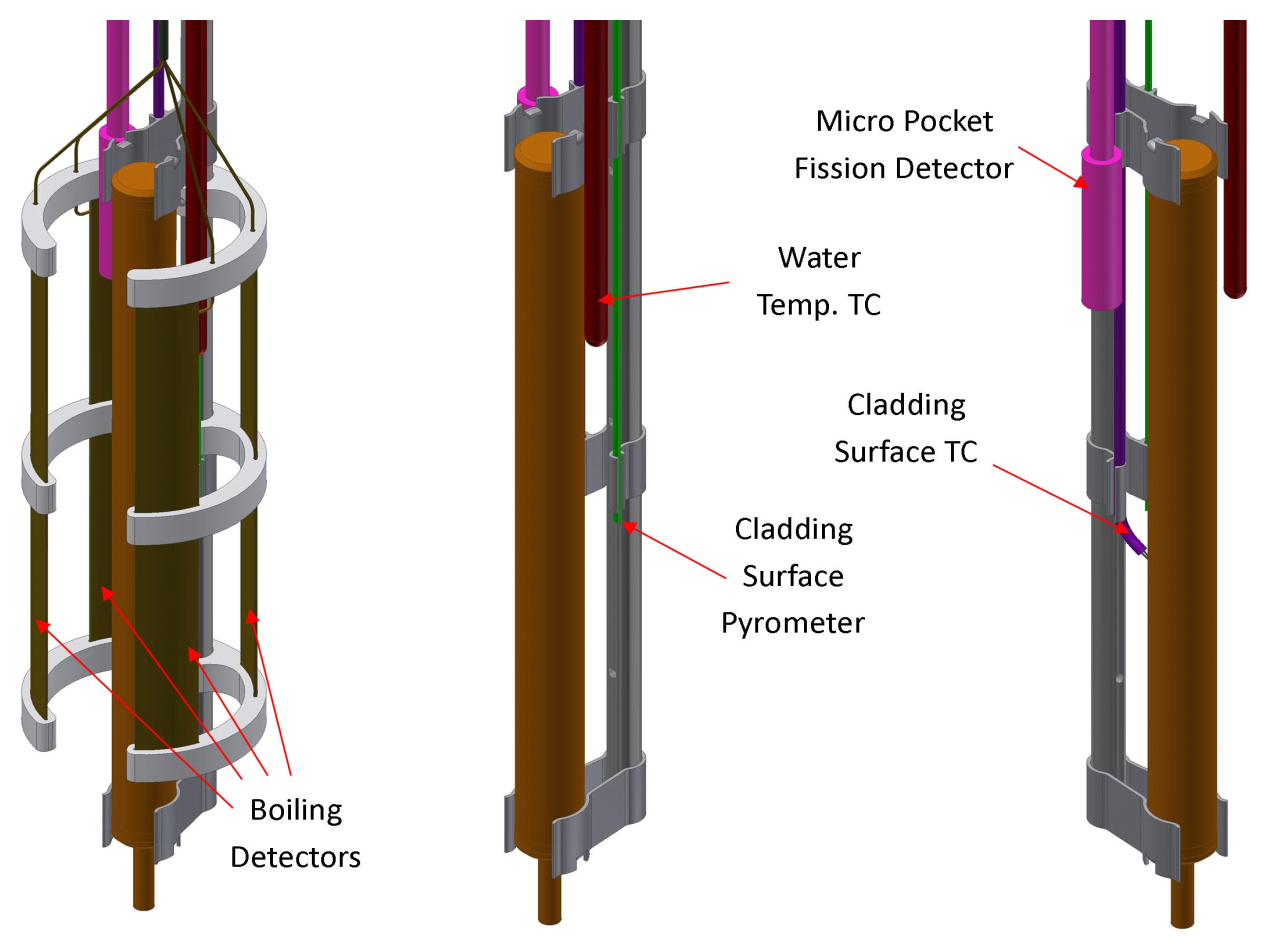

Figure 31. Sensor locations near the fuel specimen in the Multi-SERTTA irradiation test vehicle for ATF-3; MPFD shown in purple

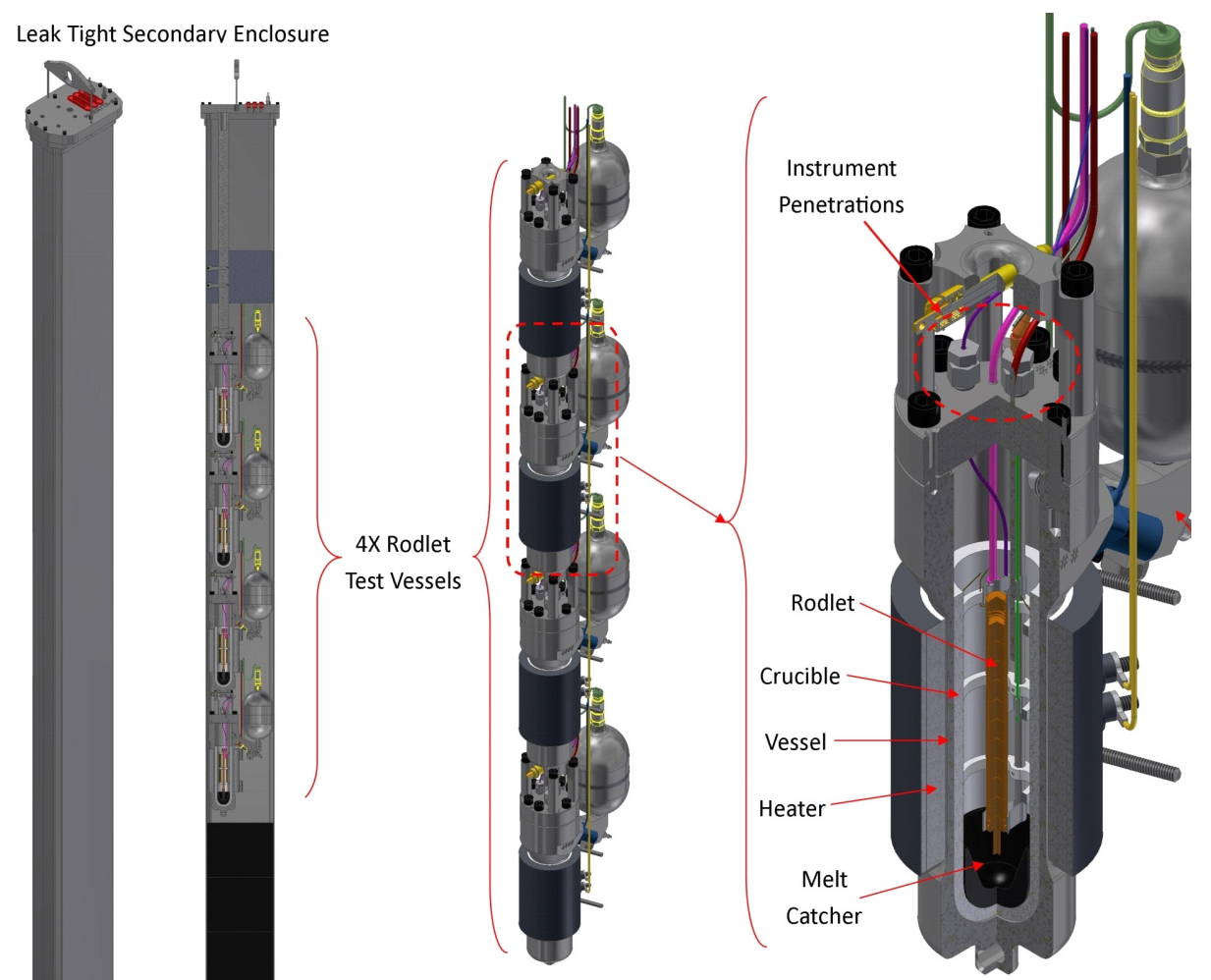

Figure 32. Overall layout of the Multi-SERTTA irradiation test vehicle for ATF-3; MPFD shown in purple on right 


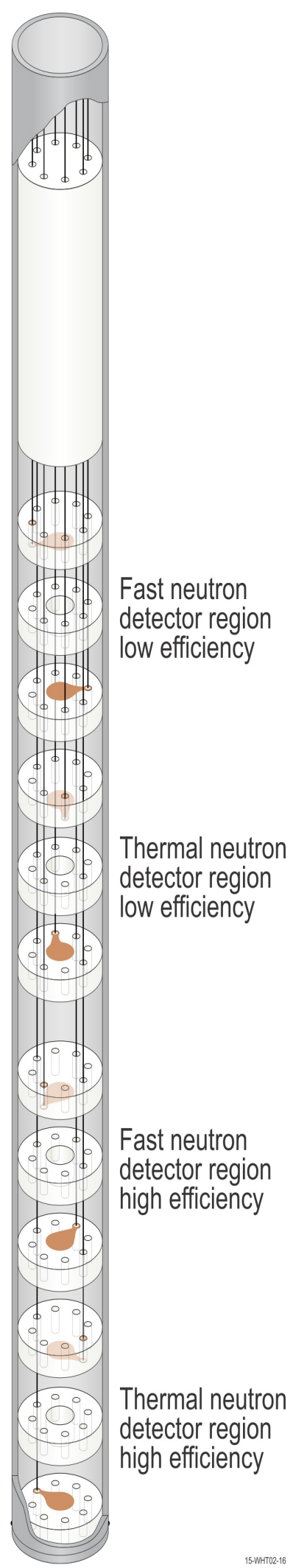

Figure 33. Transient MPFD for ATF-3 multi-SERTTA TREAT irradiation 
NEET Enhanced Micro-Pocket Fission Detector for High Temperature Reactors - FY15 Status Report 


\section{SUMMARY}

All project objectives for year one of this three year project were met and all planned FY15 activities were completed. This section summarizes the objectives, accomplishments, importance, and future work of this NEET ASI project.

\subsection{Project Objectives}

The project objectives were carefully chosen to develop a sensor that will significantly advance flux detection capabilities for irradiation tests in US MTRs. The objectives for FY15 include:

- Project kickoff meeting at KSU.

- Refine MPFD design for high temperatures up to $800^{\circ} \mathrm{C}$.

- Select and procure new high temperature compatible materials for HT MPFD construction.

- Refine MPFD construction methods for high temperatures up to $800{ }^{\circ} \mathrm{C}$.

- Refine amplifier design to be compatible with the HT MPFD.

- Refine electrode deposition for high temperatures up to $800{ }^{\circ} \mathrm{C}$.

- Refine fissile material deposition system and methods for HT MPFD fissile deposition.

- Interface with various DOE-NE programs interested in HT MPFD irradiation testing.

- Submit FY15 project report and publications on MPFD development

\subsection{Accomplishments}

The research completed in year one of this three year project is well on its way to providing an robust sensor for DOE-NE irradiation testing programs. Highlights from FY15 research accomplishments include:

- A joint collaboration was initiated between INL, KSU, and CEA. Note that CEA is participating at their own expense because of interest in this unique new sensor.

- A project meeting was held at KSU to discuss the roles and responsibilities between INL and KSU for development of the HT MPFDs.

- An updated HT MPFD design was developed.

- Selected and procured new high temperature compatible materials for HT MPFD construction.

- Construction methods to support the new design were evaluated.

- Performed laboratory evaluations of construction methods of HT MPFD.

- Electrical contact and fissile material plating performed.

- Updated detector electronics evaluations.

- Publication of MPFD technology accepted.

- Provide input to NGNP AGR 5/6/7 irradiation program for installation of HT MPFD in irradiation test.

- Provide input to ATF-2 irradiation program for installation of HT MPFD in sensor qualification test.

- Provide input the ATF-3 irradiation program for installation of a transient MPFD design in the multi-SERTTA irradiation test vehicle.

As noted within this report, this is year one of a three year project. Initial work is underway with future work scheduled to finish development and evaluate the HT MPFD in a variety of testing conditions. In addition to the evaluations planned in this project, the HT MPFD will be installed in ATR and TREAT irradiation tests as part of other DOE-NE programs evaluating the performance of candidate new fuels and materials to better characterize irradiation test conditions. 


\subsection{Importance of Superior Flux Detector}

When implemented, these sensors will significantly advance flux detection capabilities for irradiation tests in US MTRs. Specifically, deployment of HT MPFDs will address several challenges faced in irradiations performed at MTRs:

- Current fission chamber technologies do not offer the ability to measure fast flux, thermal flux, and temperature within a single compact probe; HT MPFDs offer this option.

- HT MPFD construction is very different than current fission chamber construction; the use of high temperature materials and unique design characteristics allow HT MPFDs to be specifically tailored to survive harsh conditions encountered in high performance MTR irradiation tests.

- The higher accuracy, high fidelity data available from the compact HT MPFD will significantly enhance efforts to validate new high-fidelity reactor physics codes and new multi-scale, multi-physics codes.

- HT MPFDs can be built with variable sensitivities to survive the lifetime of an experiment or fuel assembly in some MTRs, allowing more efficient and cost effective power monitoring over a wide range of reactor powers.

- The small size of the MPFD technology allows multiple sensors to be deployed, offering the potential to accurately measure flux and temperature profiles in the reactor.

\subsection{Future Work}

Further research to be completed in FY16 and FY17 will focus on finalizing construction and evaluating the HT MPFD in a variety of testing conditions. These conditions include continued high temperature furnace and autoclaves evaluations up to temperatures of $800{ }^{\circ} \mathrm{C}$. Material and construction integrity will be verified along with accompany electronic readout reliability. In addition, analysis models for sensor performance will be developed and the HT MPFD evaluations will be used to benchmark the analysis models. The HT MPFD design will be further refined as needed and prior evaluations will be repeated to compare and contrast refinements.

In addition to the development of the HT MPFD in this NEET ASI project, other DOE-NE irradiation programs are requesting MPFDs to be included in their irradiation tests. The NGNP program is actively pursuing instrumenting the graphite in the top capsule in an upcoming fuel irradiation, AGR-5/6/7, with a HT MPFD. This evaluation will further demonstrate the usefulness of the MPFD technology to simultaneously measure fast flux, thermal flux and temperature in an typical ATR long duration irradiation test. This is a significant opportunity for the HT MPFD project because the irradiation expense of a long-term MTR experiment could not be included in the original project scope.

The Accident Tolerant Fuels (ATF) program is pursuing the MPFD technology for two irradiations in the ATF-2 and ATF-3 irradiation programs. The first irradiation will evaluate a HT MPFD in the ATR during a sensor qualification test. The ATF-2 irradiation program is funding the construction, installation and testing of a these HT MPFDs (along with other advanced sensors) during these irradiations. The second irradiation will evaluate a specialized version of the MPFD technology that is suitable for TREAT transients. This version of the MPFD is scheduled to be installed in the multi SRERTTA irradiation test vehicle for calibration of irradiation conditions. Although the transient-specific MPFD developed by ATF-3 will be different from the HT MPFD design, it is expected that the information gained in the irradiation of a transient-specific MPFD will aid in developing a robust HT MPFD that can survive a variety of irradiation conditions. 


\section{REFERENCES}

1. T. Unruh, J. Rempe, D. McGregor, P. Ugorowski, M.Reichenberger, NEET Micro-Pocket Fission Detector - FY 2012 Status Report, INL/EXT-12-27274, September 2012.

2. T. Unruh, J. Rempe, D. McGregor, P. Ugorowski, M.Reichenberger, T. Ito, NEET Micro-Pocket Fission Detector - FY 2013 Status Report, INL/EXT-13-29246, September 2013.

3. T. Unruh, J. Rempe, D. McGregor, P. Ugorowski, M.Reichenberger, T. Ito, J-F Villard, NEET Micro-Pocket Fission Detector - Final Project Report, INL/EXT-14-33026, September 2014.

4. US Department of Energy, Office of Nuclear Energy, "Nuclear Energy Enabling Technologies Office of Nuclear Energy Advanced Sensors and Instrumentation Integrated Research Plan," September 2012.

5. N. Tsoulfanidis, Measurement and Detection of Radiation, 2nd Ed. Taylor \& Francis, Washington, D.C., 1993.

6. C. Jammes, P. Filliatre, B. Geslot, L. Oriol, F. Berhouet, J.-F. Villard, et L. Vermeeren, "Research Activities in Fission Chamber Modeling in Support of the Nuclear Energy Industry", IEEE Transactions on Nuclear Science, 2010.

7. B. Geslot, F. Berhouet, L. Oriol, S. Bréaud, C. Jammes, P. Filliatre, et J.F. Villard, "Development and manufacturing of special fission chambers for in-core measurement requirements in nuclear reactors", Advancements in Nuclear Instrumentation Measurement Methods and their Applications (ANIMMA), 2009.

8. M.F. Ohmes, D.S. McGregor, J.K. Shultis, P.M. Whaley, A.S.M. Sabbir Ahmed, C.C. Bolinger, T.C. Pinsent, "Development of Micro-Pocket Fission Detectors (MPFD) for Near-Core and In-Core Neutron Flux Monitoring," Proc. SPIE, Vol. 5198 (2003) pp. 234-242.

9. D.S. McGregor, J.K. Shultis, M.F. Ohmes, A.S.M.S. Ahmed, R. Ortiz, K Hoffert, "Micro-Pocket Fission Detectors (MPFD) for Near-Core and In-Core Neutron Flux Monitoring," ANS 4th Topical Meeting NPIC \& HMIT, Columus, Ohio, September 19-22, 2004.

10. D.S. McGregor, M.F. Ohmes, R.E. Ortiz, A.S.M.S. Ahmed, and J.K. Shultis, "Micro-Pocket Fission Detectors (MPFD) for In-Core Neutron Flux Monitoring," Nuclear Instruments and Methods, A554 (2005) pp. 494-499.

11. M.F. Ohmes, D.S. McGregor, J.K. Shultis, A.S.M.S. Ahmed, R. Ortiz, R.W.Olsen, "Recent Results and Fabrication of Micro-Pocket Fission Detectors," Proc. SPIE, 6319 (2006) pp. 1P1 - 1P9.

12. D.S. McGregor, "Near-Core and In-Core Neutron Radiation Monitors for Real Time Neutron Flux Monitoring and Reactor Power Levels Measurements," NERI Final Report 2002-174, 2006

13. M. F. Ohmes, J. K. Shultis, D. S. McGregor, "3D Real-Time in-Core Neutron Flux Mapping with Micro-Pocket Fission Detectors (MPFD)," IEEE Nuclear Science Symposium, Waikiki, Hawaii, Oct. 28-Nov. 3, 2007.

14. T. Unruh, J. Rempe, D. McGregor, D. Knudson, P. Ugorowski, Invention Disclosure Record, Micro Pocket Fission Detector, BA-784, March 2013. 
15. Standard Test Methods for Sheathed Thermocouples and Sheathed Thermocouple Cable, ASTM E839-11, November 2011.

16. Kansas State University, "SMART Laboratory" http://www.mne.ksu.edu/research/centers/SMARTlab/mission, Accessed August 15, 2012.

17. Kansas State University, "TRIGA Mark II Reactor Facility" http://www.mne.ksu.edu/research/centers/reactor/, Accessed August 15, 2012.

18. Kansas State University, "Electronics Design Laboratory" http://www.k-state.edu/ksuedl/, Accessed August 15, 2012.

19. Idaho National Laboratory, "High Temperature Test Laboratory" https://inlportal.inl.gov/portal/ server.pt/community/distinctive_signature_icis/315/httl, Accessed August 15, 2012.

20. Idaho National Laboratory, "INL News Release” https://inlportal.inl.gov/portal/server.pt/community/newsroom/257, Accessed August 15, 2012.

21. Qualification of Devices for Neutron Flux Measurements in the Advanced Test Reactor and the Critical Facility, Rev. 1, TEV-885, July 11, 2011.

22. Idaho National Laboratory, "Health Physics Instrument Laboratory" http://www.hpicorg.com/downloads/HP\%20Instrument\%20Lab\%20at\%20INL.pdf, Accessed August 15, 2012

23. ATRC Neutron Detector Testing Quick Look Report, INL/EXT-13-29896, September 2013.

24. T. Unruh, B. Chase, J. Rempe, D. Nigg, G. Imel, J. Harris, T. Sherman, and J.F. Villard, In-core Flux Sensor Evaluations at the ATR Critical Facility, Nuclear Technology: Vol. 187 No. 3 pp 308-315, September 2014.

25. Initial Back-to-Back Fission Chamber Testing in ATRC, INL/EXT-14-31830, June 2014.

26. M.A. Reichenberger, T.C. Unruh, P. Ugorowski, T. Ito, J.A. Roberts, S.R. Stevenson, D.M. Nichols, D.S. McGregor, "Micro-Pocket Fission Detectors (MPFDs) for In-Core Neutron Detection", Annals of Nuclear Energy, accepted August 2015.

27. N. Woolstenhulme, et al., "Fuel Cycle Research and Development ATF Design for Transient Testing", ATF Integration Meeting, August 2015. 